\title{
Static and dynamic rocking stiffness of shallow footings on sand: centrifuge modelling
}

\section{Damoun Taeseri MSC}

PhD student, Institute for Geotechnical Engineering, ETH Zurich, Switzerland (corresponding author: taeserid@ethz.ch)

Jan Laue PhD

Professor, Luleå University of Technology, Sweden

Panagiotis Martakis MSC

MSc graduate, ETH Zurich, Switzerland

\author{
Eleni Chatzi PhD \\ Associate Professor, Institute of Structural Engineering, ETH Zurich, \\ Switzerland
}

loannis Anastasopoulos PhD

Professor, Institute for Geotechnical Engineering, ETH Zurich, Switzerland

Small-strain foundation response has mostly been studied analytically, with limited experimental verification against $1 \mathrm{~g}$ physical model tests. This paper revisits the problem of small-strain foundation response, conducting a series of centrifuge model tests, aiming to eliminate the limitations of $1 \mathrm{~g}$ testing. A centrifuge modelling technique is developed, combining static pushover and dynamic impulse testing for similar systems. To allow for derivation of meaningful insights, a novel procedure for in-flight measurement of the distribution of shear modulus with depth is also developed. The latter combines spectral analysis of surface waves (SASW) measurement of the shear modulus $G_{0}$ at the surface, and estimation of the distribution of the shear modulus $G$ with depth using acceleration measurements in shaking tests. A novel centrifuge tube-actuator is developed and employed to discharge spherical projectiles against single-degree-of-freedom models lying on shallow foundations on sand. This allows generating dynamic impulse excitation, which is used to measure the small-strain dynamic rocking stiffness. The developed actuator is versatile, and was also used for in-flight SASW testing. The centrifuge model tests are shown to confirm the widely used and well-known formulas. This good agreement can also be seen as a confirmation of the validity of the developed experimental techniques.

\section{Notation}

A

$(A)$

$A_{i}$

$a_{0}$

$a_{i}$

B

(B)

b

(C)

c

D

$d$

$d_{\text {top }}$

$d h$

$d z$

$F_{\text {act }}$

$F_{\mathrm{s}}$

$f_{\mathrm{n}}$

$G_{A i}$

$G_{\max , 0}$

$G_{\max }(z)$ area of the square-shaped foundation $\left(\mathrm{m}^{2}\right)$ location insertion spherical projectile (dimensionless)

frequency domain of acceleration $(\mathrm{Hz})$

dimensionless frequency

accelerometers (dimensionless)

total width of the square-shaped foundation (m)

location tube curvature (dimensionless)

half of the width of the square-shaped foundation (m)

location connection tube with actuator

(dimensionless)

unit cohesion $\left(\mathrm{kN} / \mathrm{m}^{2}\right)$

diameter triaxial sample $(\mathrm{mm})$

diameter opening diffuser (mm)

diameter of the head of the structure $(\mathrm{m})$

height of the triaxial sample $(\mathrm{mm})$

depth of the foundation (m)

force measured by the actuators during monotonic push over $(\mathrm{kN})$

safety factor (dimensionless)

natural frequency soil structure system $(\mathrm{Hz})$

cross-spectrum (dimensionless)

maximal (elastic) shear modulus at the surface $(\mathrm{kPa})$

maximal (elastic) shear modulus distribution with the depth $(\mathrm{kPa})$

\begin{tabular}{|c|c|}
\hline$H$ & horizontal force $(\mathrm{kN})$ \\
\hline$H_{\mathrm{s}}$ & height of the column (m) \\
\hline$h$ & height of the head of the structure $(\mathrm{m})$ \\
\hline$h_{\mathrm{cg}, 1}$ & $\begin{array}{l}\text { distance between the bottom of the structure and } \\
\text { the actuator }(\mathrm{m})\end{array}$ \\
\hline$h_{\mathrm{cg}, 2}$ & $\begin{array}{l}\text { distance between the bottom of the structure and } \\
\text { the head of structure }(\mathrm{m})\end{array}$ \\
\hline$h_{\mathrm{L}}$ & vertical distance between laser 1 and $2(\mathrm{~m})$ \\
\hline$h_{\mathrm{t}}$ & air pluviation height $(\mathrm{cm})$ \\
\hline$I_{\mathrm{d}}$ & density index (dimensionless) \\
\hline$K_{\text {column }}$ & stiffness column (MN m) \\
\hline$K_{\mathrm{r}}$ & rotational stiffness (MN m) \\
\hline$K_{\mathrm{r}, \text { Static }}$ & static rotational stiffness $(\mathrm{MN} \mathrm{m})$ \\
\hline$L_{1}$ & horizontal displacement measured by laser $1(\mathrm{~m})$ \\
\hline$L_{2}$ & horizontal displacement measured by laser $2(\mathrm{~m})$ \\
\hline$M$ & $\begin{array}{l}\text { mobilised moment by the rotation of the } \\
\text { superstructure }(\mathrm{kN} \mathrm{m})\end{array}$ \\
\hline$M_{\mathrm{AC}}$ & slope axial compression (dimensionless) \\
\hline$M_{\max }$ & maximal mobilised moment (MN m) \\
\hline$M_{\text {ult }}$ & ultimate moment capacity (MN m) \\
\hline$m_{\text {top }}$ & mass of the head $(t)$ \\
\hline$m_{\text {tot }}$ & total mass of the superstructure foundation system $(t)$ \\
\hline$N_{\mathrm{c}}, N_{\mathrm{q}}, N_{\gamma}$ & bearing capacity factors (dimensionless) \\
\hline$p_{\mathrm{cv}}^{\prime}$ & mean effective stresses $\left(\mathrm{kN} / \mathrm{m}^{2}\right)$ \\
\hline$q$ & vertical pressure below the foundation $\left(\mathrm{kN} / \mathrm{m}^{2}\right)$ \\
\hline$q_{\mathrm{cv}}$ & deviatoric stresses $\left(\mathrm{kN} / \mathrm{m}^{2}\right)$ \\
\hline
\end{tabular}


International Journal of Physical Modelling in Geotechnics Volume 18 Issue 6
Static and dynamic rocking stiffness

of shallow footings on sand:

centrifuge modelling

Taeseri, Laue, Martakis, Chatzi and

Anastasopoulos $q_{\mathrm{f}} \quad$ ultimate bearing capacity stress $\left(\mathrm{kN} / \mathrm{m}^{2}\right)$

$s_{\mathrm{c}}, s_{\mathrm{q}}, s_{\gamma} \quad$ shape factors (dimensionless)

$s_{\mathrm{r}} \quad$ degree of saturation (dimensionless)

$t \quad$ time (s)

$t(f) \quad$ wave propagation travel time (s)

$u_{i} \quad$ horizontal displacement of the accelerometers $(\mathrm{m})$

$V \quad$ vertical weight of the foundation-structure system $(\mathrm{kN})$

$V_{\mathrm{s}, 0} \quad$ shear wave velocity at the surface $(\mathrm{m} / \mathrm{s})$

$w \quad$ depositional intensity $\left(\mathrm{g} /\left(\mathrm{min} / \mathrm{cm}^{2}\right)\right)$

$w_{\mathrm{c}} \quad$ water content $(\%)$

$\alpha \quad$ parameter for the parabolic distribution of the shear modulus (dimensionless)

$\gamma_{\mathrm{d}} \quad$ unit dry weight soil $\left(\mathrm{kN} / \mathrm{m}^{3}\right)$

$\gamma_{i, i+1}(t) \quad$ average shear strain between two accelerometers

(dimensionless)

$\theta \quad$ rotation superstructure (rad)

$v \quad$ speed displacement controlled triaxial experiment (dimensionless)

unit dry mass soil $\left(\mathrm{kg} / \mathrm{m}^{3}\right)$

confining pressure $\left(\mathrm{kN} / \mathrm{m}^{2}\right)$

axial stress triaxial experiments $\left(\mathrm{kN} / \mathrm{m}^{2}\right)$

lateral stress triaxial experiments $\left(\mathrm{kN} / \mathrm{m}^{2}\right)$

shear stress soil at the depth $z(\mathrm{kPa})$

phase difference (rad)

effective internal frictional angle at constant

volume $\left({ }^{\circ}\right)$

$\phi_{\text {peak }}^{\prime} \quad$ effective internal frictional angle at peak ( $\left.{ }^{\circ}\right)$

$\omega_{\mathrm{n}} \quad$ natural angular frequency $(1 / \mathrm{s})$

\section{Introduction}

The concept of soil-structure interaction (SSI) was introduced almost 40 years ago (Luco and Contesse, 1973). Despite the extensive research on the subject (a comprehensive summary can be found in Kausel, 2010 or Sieffert and Cevaer, 1995), the concept of elastic SSI has been considered beneficial in terms of seismic performance, and many seismic codes considered its omission as a conservative simplification (NEHRP, 1997). SSI increases the flexibility of the soil-foundationstructure system, leading to a corresponding increase of the fundamental period of the system. Moreover, due to the additional material and radiation damping offered by the soil, the overall damping of the soil-foundation-structure system is increased. Since the acceleration design spectra decrease monotonically with the period of the system, an increase of the period and damping can only lead to a decrease of spectral accelerations.

Although these assumptions can be reasonable for relatively light structures founded on stiff soil, they are not necessarily in the case of heavier and tall structures (such as bridges) on compliant soil. Real acceleration response spectra do not decrease monotonically with the period, and the effect of SSI can very well be detrimental (Ciampoli and Pinto, 1995; Mylonakis and Gazetas, 2000). The predominant period of the ground motion could resonate with the elongated period of the soil-foundation-structure system, leading to an increase of ductility demand. Many case histories have proven that SSI can indeed be detrimental, among which the collapse of the $630 \mathrm{~m}$ Fukae section of Hanshin Expressway during the notorious $1995 \mathrm{M}_{\mathrm{w}} 7$ Kobe earthquake (Gazetas et al., 2006), and the systematic severe damage of collapse of 6- to 20-storey buildings in Mexico City during the devastating $1985 \mathrm{M}_{\mathrm{w}} 8 \cdot 1$ Michoacan earthquake (Kramer, 1996). In both cases, the elongation of the period due to SSI led to resonance with the ground motion, as well as dramatic increase of spectral accelerations and ductility demand.

More recently, non-linear SSI has attracted the attention of the engineering community. Several studies have addressed the seismic response of surface and embedded foundations. A review of relevant such studies can be found in Lou et al. (2011). In the last decade, rocking foundations have also been extensively studied, analytically and experimentally (Anastasopoulos et al., 2010, 2012; Antonellis et al., 2015; Deng and Kutter, 2012; Gajan and Kutter, 2008; Gajan et al., 2005; Gazetas et al., 2003; Kokkali et al., 2014; Mergos and Kawashima, 2005; Paolucci et al., 2007; Pecker, 2003; Pecker and Chatzigogos, 2010). Some of these studies have dealt with rocking stiffness degradation at large deformations (i.e. rotations) and the influence of the factor of safety against static loading on the degradation rate (Anastasopoulos et al., 2012; Deng and Kutter, 2012). Overall, the research on the subject suggests that non-linear SSI and 'yielding' at the soil-foundation level under strong seismic loading can be beneficial for the performance of the structure.

However, most prevalent and currently constructed structures are designed following the principles of foundation capacity design of current seismic codes, according to which the foundation is over-designed, guiding the 'plastic-hinge' to the superstructure. Hence, in most cases in practice, it is the small-strain stiffness and damping that can be crucial in design. In contrast to strongly non-linear response, the (quasi-) elastic small-strain response of foundations has mostly been studied analytically. Gazetas (1991a) conducted such an analytical study on the elastic response of surface foundations resting on inhomogeneous soil, and proposed charts and formulas for the estimation of foundation stiffnesses. Erden (1974) and Gazetas and Stokoe (1991) conducted small-scale (1g) experiments of surface foundations on moist sand, aiming to validate the analytical solutions. While the results of the experiments were in close agreement with the analytical solutions for vertical oscillations, in the case of swaying-rocking, the measured damping was only half of the theoretical derived. While this 
International Journal of Physical Modelling in Geotechnics Volume 18 Issue 6
Static and dynamic rocking stiffness

of shallow footings on sand:

centrifuge modelling

Taeseri, Laue, Martakis, Chatzi and

Anastasopoulos was mainly attributed to boundary conditions, the inherent inability of $1 \boldsymbol{g}$ testing to realistically reproduce soil confining pressures could have been an additional factor.

Given that soil strength and stiffness depend on the effective confining stress and stress history, testing replicas at a $1 g$ environment has some limitations (Schofield, 1980). Soil properties are a function of effective confining stresses, owing to the soil's self-weight. When modelling a geotechnical system at a scale of $1: N$, the confining stresses are $N$ times smaller than the prototype, leading to scale effects. To achieve appropriate stress levels, a geotechnical centrifuge can be used to artificially increase the self-weight of the physical model by applying an increased 'gravitational' acceleration. In this way, a 1:N scale model tested at $\mathbf{N g}$ in a centrifuge will have the same effective stresses as the full-scale prototype. This paper revisits the problem of quasielastic small-strain foundation stiffness response, by conducting a series of centrifuge model tests. The key objective is to eliminate the aforementioned limitations of $1 \mathrm{~g}$ testing.

The paper experimentally investigates soil-foundationstructure interaction (SFSI) for surface footings on sand, focusing on the static and dynamic rocking stiffness at small strains. To this end, monotonic pushover and dynamic centrifuge mode tests were conducted at the geotechnical drum centrifuge of ETH Zurich (Springman et al., 2001), under increased gravitational field of $60 \mathrm{~g}$ and $100 \mathrm{~g}$. The monotonic pushover tests serve two purposes: (a) to investigate the rocking stiffness at the elastic small-strain regime and $(b)$ to examine the ultimate moment capacity of the footings. Dynamic loading is considered to be the most challenging and a novel part of the presented work. For this purpose, a novel centrifuge-mounted tube-actuator was developed and used to subject the soil-foundation-structure system to dynamic impulse excitation (Martakis et al., 2016). An additional contribution of the paper is the development of a reliable technique for in-flight measurements of the distribution of soil stiffness with depth.

\section{Methodology}

The work presented in this paper is a first part of an exhaustive experimental study, aiming to derive insights on the seismic performance of shallow and embedded foundations on plane and sloped soil. The overall work includes: $(a)$ monotonic and cyclic pushover tests; $(b)$ dynamic impulse excitation tests; and (c) dynamic seismic shaking tests. The first two types of tests were conducted at the ETH Zurich drum centrifuge. The seismic shaking centrifuge model tests were conducted at the geotechnical beam centrifuge of the University of California at San Diego (UCSD), which is equipped with an on-board seismic shaker. Such a shaker is not available for the drum centrifuge of ETH Zurich, and this has led to this collaboration.
The present paper focuses on the development of a new experimental technique, on the dynamic response shallow foundations. The first part of the paper describes the experimental procedure for in-flight measurement of the distribution of shear modulus with depth. The second part develops the experimental method for measurement of static pushover and dynamic impulse testing, with the latter constituting the main novelty of the paper. All of the tests documented herein (monotonic pushover and dynamic impulse excitation) were conducted at the ETH Zurich drum centrifuge. The shaking table tests conducted at the beam centrifuge of UCSD are also discussed, as they form part of the developed experimental procedure to measure the distribution of soil shear modulus with depth.

\subsection{Overview of experimental set-up}

The centrifuge model tests were conducted under centrifugal accelerations of $60 \mathrm{~g}$ and $100 \mathrm{~g}$, at the geotechnical drum centrifuge facility of ETH Zurich. As discussed by Springman et al. (2001), the geotechnical drum centrifuge of ETH Zurich was manufactured by Thomas Broadbent \& Sons Ltd and can reach a maximum centrifugal acceleration of $440 \mathrm{~g}$ carrying a payload of $2 \mathrm{t}$. The prototype dimensions were scaled down according to the centrifuge scaling laws of Table 1. Unless specified otherwise, all geometrical attributes and test results are presented in prototype scale. As shown in Figure 1, the most relevant parts of the drum centrifuge are the tool platform and the drum channel. The soil model is placed in the drum channel, while instrumentation and actuators can both be installed on the tool platform and in the channel. Twin concentric shafts allow separate independent control of the central tool platform and the drum channel. This allows conducting several tests along the circumference of the drum channel in one run while it is possible to stop the tool table without stopping the channel.

The drum channel features an external diameter of $2 \cdot 2 \mathrm{~m}$, a height of $0.7 \mathrm{~m}$ and a depth of $0.3 \mathrm{~m}$. By filling the entire channel with soil, at $440 \mathrm{~g}$, the model would correspond to a prototype problem of $132 \mathrm{~m}$ depth, $308 \mathrm{~m}$ width and $2.2 \mathrm{~km}$ length (Springman et al., 2001). Nonetheless, this major advantage comes along with a significant limitation. Filling of the entire drum channel with soil needs to be performed in-flight

Table 1. Geotechnical centrifuge scaling laws

\begin{tabular}{lc} 
Parameter & Model/prototype \\
\hline Length & $1 / n$ \\
Acceleration & $n$ \\
Velocity & 1 \\
Strain & 1 \\
Force & $1 / n^{2}$ \\
Mass & $1 / n^{3}$ \\
Time & $1 / n$ \\
Frequency & $n$
\end{tabular}


International Journal of Physical Modelling in Geotechnics Volume 18 Issue 6
Static and dynamic rocking stiffness

of shallow footings on sand:

centrifuge modelling

Taeseri, Laue, Martakis, Chatzi and

Anastasopoulos
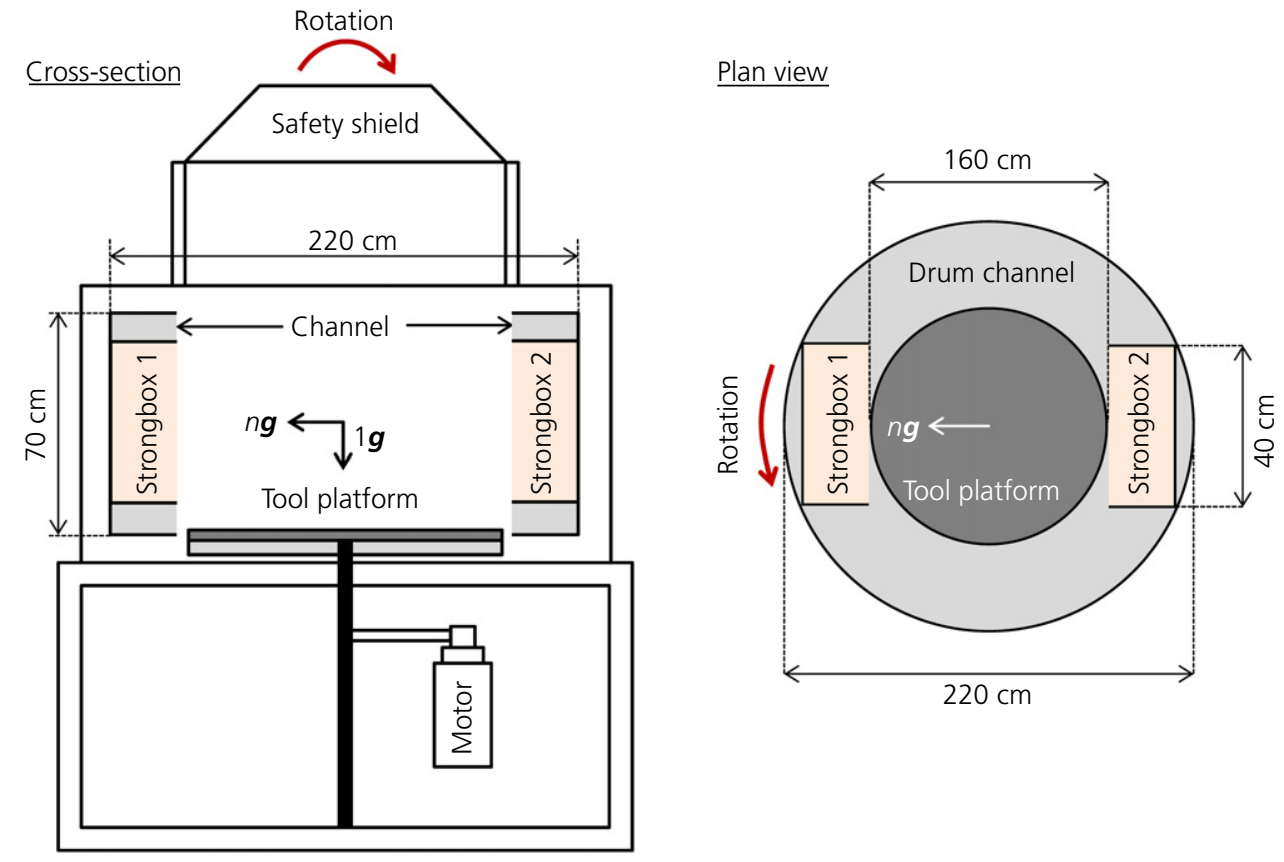

Figure 1. Schematic representation of the geotechnical drum centrifuge of ETH Zurich

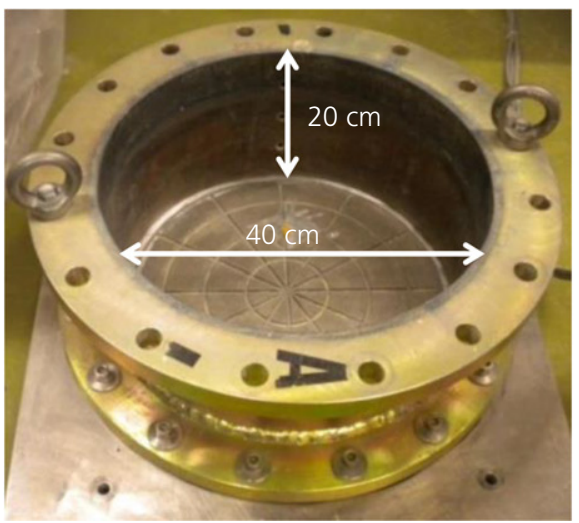

(a)

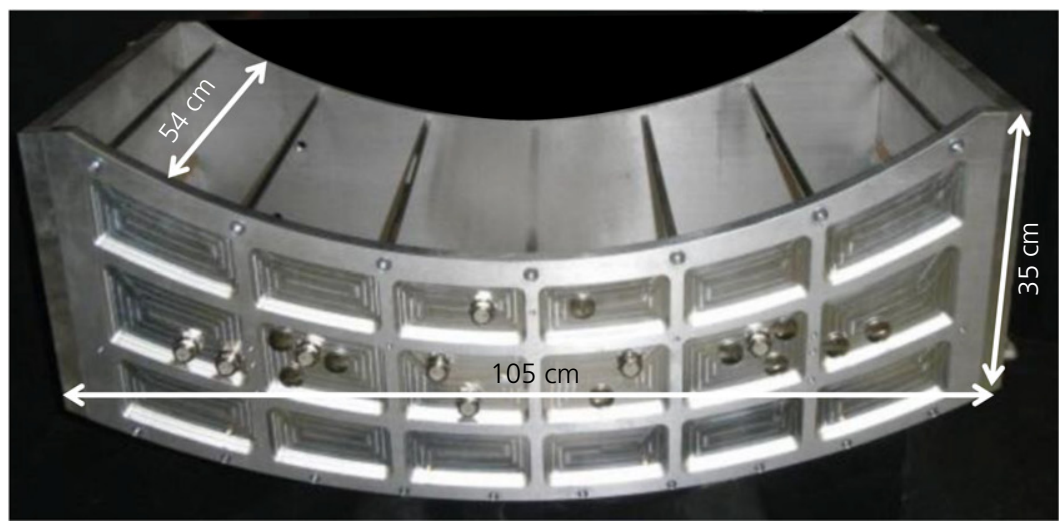

(b)

Figure 2. Strongboxes utilised for the experiments at the geotechnical drum centrifuge of ETH Zurich: (a) cylindrical and (b) semi-circular

at an enhanced gravitational level, so that the soil model remains under equilibrium. Such in-flight soil pluviation is technically challenging and time consuming (Laue et al., 2002). In order to reduce the technical difficulties of in-flight soil pluviation, an alternative technique has been developed (Laue et al., 2015; Nater, 2002), which was applied for the tests conducted herein. Two strongboxes were installed on the drum channel, positioned one opposite to the other (at $180^{\circ}$ ) for balance. As illustrated in Figure 2, two different strongboxes were used for the experiments: (a) cylindrical boxes of $40 \mathrm{~cm}$ diameter and $20 \mathrm{~cm}$ depth (model scale), for dynamic impulse excitation tests (Figure 2(a)); and (b) larger semi-circular boxes of $105 \mathrm{~cm}$ length, $35 \mathrm{~cm}$ width and $54 \mathrm{~cm}$ height (model scale) for monotonic pushover tests (Figure 2(b)). The installation locations of the strongboxes in the drum channel are schematically illustrated in the plan view of Figure 1.

The simplified technique allowed for a drastic reduction of the time needed for model preparation, also avoiding the technical difficulties related to in-flight air pluviation. The soil models 
International Journal of Physical Modelling in Geotechnics Volume 18 Issue 6
Static and dynamic rocking stiffness

of shallow footings on sand:

centrifuge modelling

Taeseri, Laue, Martakis, Chatzi and

Anastasopoulos were prepared in the strongboxes outside the centrifuge employing standard (1g) air pluviation, and were mounted afterwards in the channel. The employed air pluviation technique and a detailed description of soil model preparation are meticulously explained later on. Two models were installed and tested at the same spin. This does not only decrease the testing time, but it is also essential for retaining balance of the centrifuge. The latter is necessary in order to avoid over-stressing of the bearings, which could lead to a reduction of their service life or even failure. The nominal maximum out of balance (OOB) moment is $10 \mathrm{kgm}$ at $440 \mathrm{~g}$ at a radius of $1 \cdot 1 \mathrm{~m}$. The strongboxes were therefore carefully weighted before each test, aiming to maintain the weight difference within acceptable margins.

The data acquisition (DAQ) systems are delivered in modular form, permitting a flexible choice of sampling and recording modes. In total, 40 channels are available, allowing measurement of different quantities during the experiments. Depending on the type of experiment, two different tool-platform set-ups were employed. Figure 3 shows the platform set-up for the dynamic impulse excitation tests. In the monotonic pushover tests, the tool platform was only equipped with two high-speed cameras (one for each model). For the dynamic tests, the tool platform was also equipped with high-speed cameras and the tube-actuator. The latter consists of a plastic tube of $10 \mathrm{~mm}$ diameter, which allowed the release of spherical projectile against the head of the structure. As discussed later on, the impact of the spherical projectile on the structure led to its free vibration, allowing for measurement of the dynamic stiffness.

\subsection{Foundation-structure modelling}

Eight different footing-single-degree-of-freedom (SDOF) model configurations were tested. As summarised in Table 2, the key variables are: the weight of the structure $M(\mathrm{t})$; the width of the square foundation $B=2 b(\mathrm{~m})$; the height of the column $H_{\mathrm{s}}(\mathrm{m})$; and the height $h(\mathrm{~m})$ and diameter $d_{\text {top }}(\mathrm{m})$ of the cylindrical head of the structure. Table 2 also indicates the $g$-level at which the experiments were carried out. The characteristics of the systems tested were selected based on a conceptual prototype, representative of a medium-size bridge pier foundation, such as the one shown in Figure 4(a) (two-lane railway bridge in Zurich, Switzerland). While various foundations with different embedment ratios $D / B$ were tested, the ones discussed in this paper refer to surface foundations $(D / B=0)$. The model, along with its key variables, is sketched in Figure 4(b). Coupling effects between the rocking and the swaying mode are not of crucial importance when the slenderness ratio is large enough. In all centrifuge model tests, the slenderness ratio $\left(H_{\mathrm{s}}+h\right) / B$ was maintained larger than 1.5 (up to 2 in several cases), and therefore this is considered a reasonable simplification.

The foundation and the column of the SDOF system were made of aluminium $\left(\gamma_{\mathrm{Al}}=27.5 \mathrm{kN} / \mathrm{m}^{3}\right)$. Aluminium was chosen as it has a similar density to reinforced concrete, which

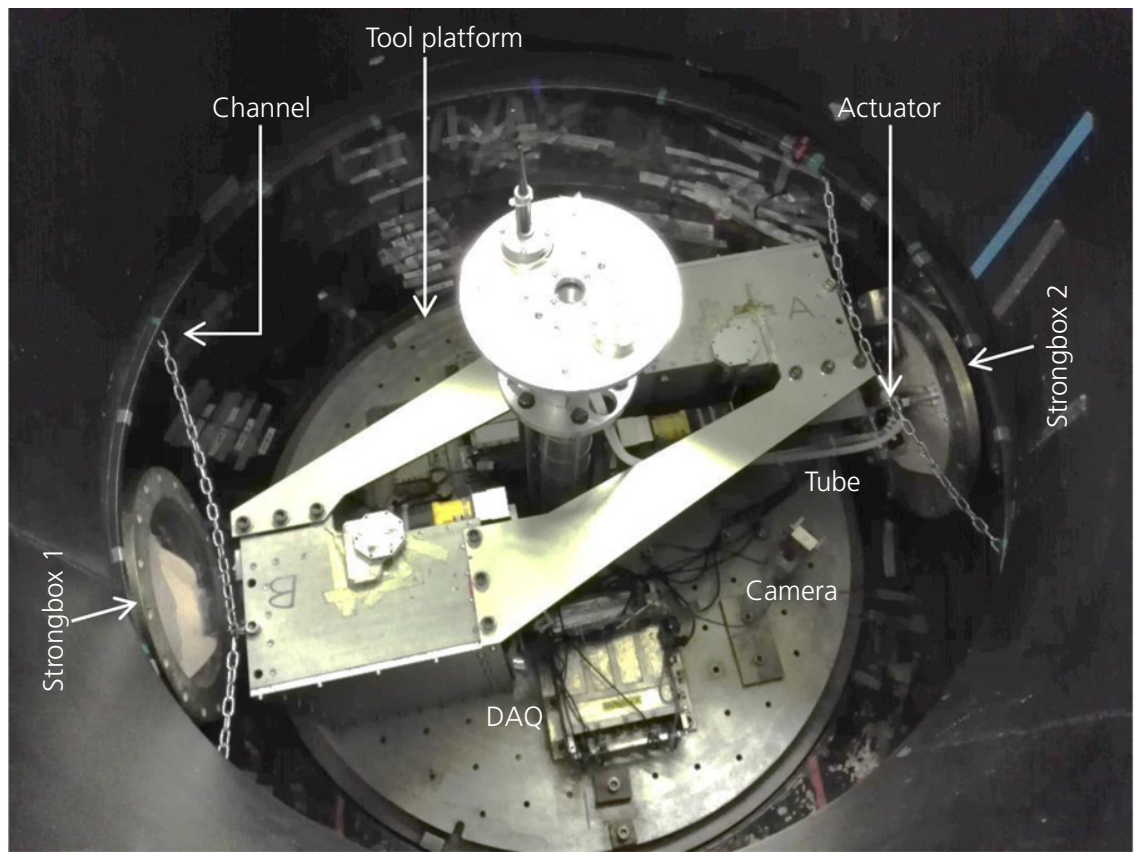

Figure 3. Tool platform utilised for the dynamic experiments at ETH Zurich 
Table 2. Summary of static and dynamic centrifuge model tests

\begin{tabular}{|c|c|c|c|c|c|c|c|c|c|c|}
\hline $\begin{array}{l}\text { Model } \\
\text { ID }\end{array}$ & $B: m$ & $H_{s}: \mathrm{m}$ & $h: m$ & $d: m$ & $\begin{array}{l}\text { Material head: } \\
\text { dimensionless }\end{array}$ & $\begin{array}{c}\text { Total weight } \\
m_{\text {Tot }}: t\end{array}$ & $\begin{array}{c}\text { Safety factor } \\
F_{s}: \text { dimensionless }\end{array}$ & $\begin{array}{c}\text { Density index } \\
I_{d:} \text { dimensionless }\end{array}$ & $\begin{array}{c}\text { Fixed base } \\
\text { frequency } \\
f_{n}: \mathrm{Hz}\end{array}$ & $\begin{array}{c}g \text {-level: } \\
\quad g\end{array}$ \\
\hline 1 & $2 \cdot 4$ & $3 \cdot 6$ & $1 \cdot 2$ & 3 & Aluminium & 33 & 12 & $0 \cdot 78$ & 29 & 60 \\
\hline 2 & $3 \cdot 0$ & $3 \cdot 6$ & $1 \cdot 2$ & 3 & Aluminium & 34 & 23 & $0 \cdot 81$ & 29 & 60 \\
\hline 3 & $4 \cdot 0$ & $6 \cdot 0$ & $2 \cdot 0$ & 5 & Aluminium & 126 & 15 & 0.77 & 16 & 100 \\
\hline 4 & $5 \cdot 0$ & $6 \cdot 0$ & $2 \cdot 0$ & 5 & Aluminium & 127 & 29 & $0 \cdot 80$ & 16 & 100 \\
\hline 5 & $2 \cdot 4$ & $3 \cdot 6$ & $1 \cdot 2$ & 3 & Steel & 96 & 4 & $0 \cdot 79$ & 17 & 60 \\
\hline 6 & $3 \cdot 0$ & $3 \cdot 6$ & $1 \cdot 2$ & 3 & Steel & 97 & 8 & 0.82 & 17 & 60 \\
\hline 7 & $4 \cdot 0$ & $6 \cdot 0$ & $2 \cdot 0$ & 5 & Steel & 370 & 5 & 0.77 & 10 & 100 \\
\hline 8 & $5 \cdot 0$ & $6 \cdot 0$ & $2 \cdot 0$ & 5 & Steel & 371 & 10 & 0.79 & 10 & 100 \\
\hline
\end{tabular}

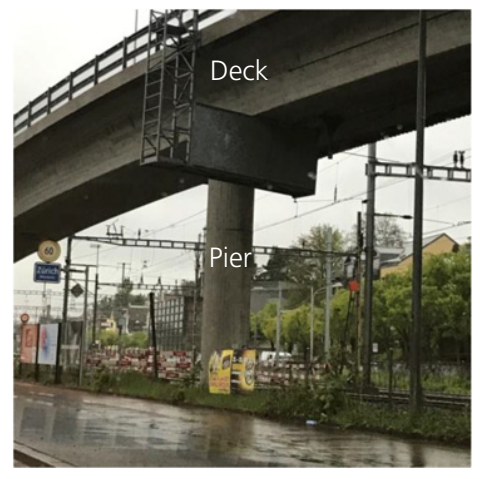

(a)

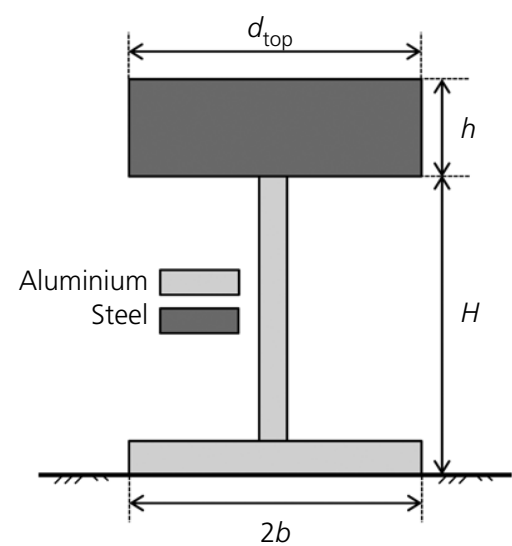

(b)

Figure 4. Outline of the studied problem: (a) bridge pier corresponding to the conceptual prototype; and (b) physical model used for the experiments, along with key model parameters

is the typical material of bridge footings. The material used for the head of the structure (corresponding to the mass of the bridge deck) was either steel or aluminium, depending on the desired target weight: $(a)$ aluminium for tests $1-4$, modelling lightly loaded structures; and $(b)$ steel $\left(\gamma_{\text {Steel }}=78.5 \mathrm{kN} / \mathrm{m}^{3}\right)$ for tests $5-8$, modelling heavily loaded structures load. The chosen combinations of materials and dimensions allow for testing of a wide range of models with factors of safety against static loading $F_{\mathrm{s}}$ ranging from 5 to 30 (Table 2). The three parts (foundation, column and head of the structure) were firmly attached to each other by means of $5 \mathrm{~mm}$ bolts. In order to focus on foundation response, a relatively large cross-section was used for the column. With such relatively large stiffness, the flexural deformation of the column is minimised. Indeed, the flexural drift was calculated and found to be 2 orders of magnitude smaller than the rotational drift, confirming that the simplification of rigid-body movement is reasonable for the cases examined. The natural frequency of the fixed base system was estimated via Equation 1 and the values are summarised in Table 2
1. $f_{\mathrm{n}}=1 / 2 \pi \sqrt{K_{\text {column }} / m_{\text {top }}}$

where $f_{\mathrm{n}}(\mathrm{Hz})$ is the natural frequency of the fixed base model, $K_{\text {column }}(\mathrm{MNm})$ the stiffness of the circular column, and $m_{\text {top }}(\mathrm{t})$ the mass of the head of the superstructure.

\subsection{Soil parameters and model preparation}

The tests were conducted using Perth sand, which has been used in several experimental campaigns and is very well documented (Arnold, 2011; Buchheister, 2012; Nater, 2007). Different samples of diameter $D=56 \mathrm{~mm}$ and height $d_{\mathrm{h}}=120 \mathrm{~mm}$ have been tested in triaxial compression tests at cell pressures $\sigma_{3}$ ranging from 50 to $400 \mathrm{kPa}$ (Nater, 2007). The key results are summarised in Table 3, while Figure 5 shows the results for a specimen of density index $I_{\mathrm{d}}=56 \cdot 1 \%$ (test ID 6 in Table 3) subjected to cell pressure $\sigma_{3}=205.4 \mathrm{kPa}$. Figure 5(a) shows the $q_{\mathrm{cv}}-\varepsilon$ (\%)diagram, while the slope $M_{\mathrm{AC}}$ in the $q_{\mathrm{cv}}-p_{\mathrm{cv}}^{\prime}$ space is depicted in Figure $5(\mathrm{~b})$. The latter is 
International Journal of Physical Modelling in Geotechnics Volume 18 Issue 6
Static and dynamic rocking stiffness

of shallow footings on sand:

centrifuge modelling

Taeseri, Laue, Martakis, Chatzi and

Anastasopoulos

used for estimation of the constant volume friction angle $\left(\phi_{\mathrm{cv}}^{\prime}\right)$, where $p_{\mathrm{cv}}^{\prime}=\left(\left(\sigma_{1}^{\prime}+2 \sigma_{3}^{\prime}\right) / 3\right)$ represents the mean effective stress at constant volume, and $q_{\mathrm{cv}}=\sigma_{1}-\sigma_{3}$ is the deviatoric stress. The values of $p_{\mathrm{cv}}^{\prime}$ and $q_{\mathrm{cv}}$ for each test are also summarised in Table 3 along with the values of the internal friction angle at peak $\phi_{\text {Peak }}^{\prime}$ and constant volume $\phi_{\mathrm{cv}}^{\prime}$. The slope of the regression line in Figure 5(b) is $M_{\mathrm{AC}}=1 \cdot 22$. For axial compression, $M_{\mathrm{AC}}=6 \sin \phi_{\mathrm{cv}}^{\prime} /\left(3-\sin \phi_{\mathrm{cv}}^{\prime}\right)$, and therefore $\phi_{\mathrm{cv}}^{\prime}=32^{\circ}$. Similarly, the same procedure was utilised for the determination of the internal peak friction angle $\phi_{\text {Peak }}^{\prime}$ and the values are summarised in Table 3. The grain size distribution and the properties of Perth sand are summarised in Figure 6 and Table 4, respectively. The grain size distribution and properties of Coronado sand are also shown for direct comparison. As discussed later on, the Coronado sand was used for the experiments conducted at UCSD, and was selected to be as close as possible to Perth sand.

Table 2 further summarises the material and geometric properties of the tested soil-foundation-structure systems. The factors

Table 3. Test parameters for the triaxial experiments on Perth sand (after Nater, 2007)

\begin{tabular}{|c|c|c|c|c|c|c|}
\hline Test ID & $I_{d}: \%$ & $\sigma_{3}^{\prime}: \mathrm{kPa}$ & $p_{\mathrm{cv}}^{\prime}: \mathrm{kPa}$ & $q_{\mathrm{cv}}: \mathrm{kPa}$ & $\phi_{\text {peak }}^{\prime}:^{\circ}$ & $\phi_{\mathrm{cv}}^{\prime}:^{\circ}$ \\
\hline 1 & $26 \cdot 8$ & $53 \cdot 1$ & 88.9 & 107.5 & 32.0 & 31.5 \\
\hline 2 & $25 \cdot 3$ & $52 \cdot 4$ & 78.9 & $79 \cdot 3$ & 32.5 & $32 \cdot 0$ \\
\hline 3 & $43 \cdot 5$ & $100 \cdot 3$ & $167 \cdot 6$ & 201.9 & $34 \cdot 5$ & $31 \cdot 0$ \\
\hline 4 & 32.5 & $98 \cdot 7$ & 159.5 & 182.5 & 33.0 & 33.0 \\
\hline 5 & $46 \cdot 0$ & $205 \cdot 2$ & 328.1 & 368.7 & $36 \cdot 0$ & $32 \cdot 0$ \\
\hline 6 & $56 \cdot 1$ & $205 \cdot 4$ & $365 \cdot 4$ & $480 \cdot 1$ & $37 \cdot 5$ & $32 \cdot 5$ \\
\hline 7 & $52 \cdot 8$ & $406 \cdot 5$ & $727 \cdot 6$ & $963 \cdot 5$ & $36 \cdot 5$ & $32 \cdot 0$ \\
\hline 8 & $80 \cdot 1$ & $401 \cdot 3$ & $629 \cdot 5$ & $684 \cdot 7$ & $39 \cdot 0$ & 31.0 \\
\hline
\end{tabular}

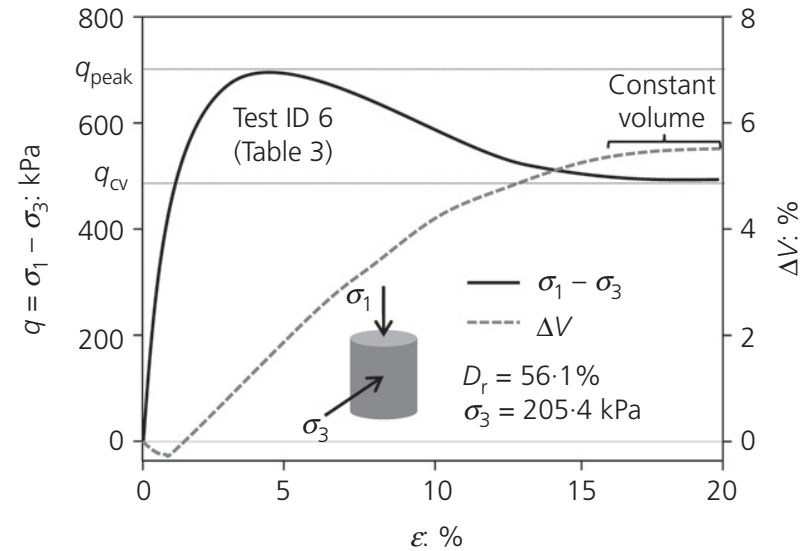

(a) of safety against static loading $F_{\mathrm{s}}$ are calculated according to the bearing capacity factors proposed by Terzaghi et al. (1996)

2. $\quad F_{\mathrm{s}}=\frac{q_{\mathrm{f}}}{q}=\frac{c N_{\mathrm{c}} s_{\mathrm{c}}+\mathrm{d} z \gamma N_{\mathrm{q}} s_{\mathrm{q}}+0.5 \gamma(2 b) N_{\gamma} s_{\gamma}}{V / A}$

where $q_{\mathrm{f}}\left(\mathrm{kN} / \mathrm{m}^{2}\right)$ is the ultimate bearing capacity stress, $q\left(\mathrm{kN} / \mathrm{m}^{2}\right)$ the vertical pressure below the foundation, $V(\mathrm{kN})$ the vertical load acting on the foundation, $A\left(\mathrm{~m}^{2}\right)$ the area of the square-shaped foundation, $c\left(\mathrm{kN} / \mathrm{m}^{2}\right)$ the unit cohesion, $\gamma\left(\mathrm{kN} / \mathrm{m}^{3}\right)$ the effective unit weight of Perth sand, $d_{z}(\mathrm{~m})$ the depth of foundation, $2 b=B(\mathrm{~m})$ the width of foundation, $s_{\mathrm{c}}, s_{\mathrm{q}}, s_{\gamma}$ (dimensionless) are the shape factors for $\phi_{\mathrm{cv}}^{\prime}=32^{\circ}$, $N_{\mathrm{c}}, N_{\mathrm{q}}, N_{\gamma}$ (dimensionless) are the bearing capacity factors for $\phi_{\mathrm{cv}}^{\prime}=32^{\circ}$.

For both monotonic pushover and dynamic impulse excitation tests, the model preparation was performed outside the drum centrifuge. The sand was prepared by dry air pluviation, reaching a target dry density $\rho_{\mathrm{d}}=1.75 \mathrm{t} / \mathrm{m}^{3}$ representing a density index of approximately $I_{\mathrm{d}} \approx 80 \%$ for all experiments (Table 2). The high-density level was made possible by maintaining a large pluviation height $h_{\mathrm{t}}$ (between 50 and $70 \mathrm{~cm}$ ), in combination with appropriate diffusers (Lo Presti et al., 1992). The adopted pluviation technique is based on the one employed by Nater (2007) and Arnold (2011). As schematically illustrated in Figure 7(a), the sand is filled in a cylindrical container of $1 \mathrm{~m}$ height and $0.45 \mathrm{~m}$ diameter. The latter has a hopper shape at the bottom, equipped with a perforated disc with a hole diameter $d=5-10 \mathrm{~mm}$, and a tube with a meshed disc at its bottom end. The sand is released from the container, flowing through the diffuser (perforated disc, tube and meshed

Figure 5. Triaxial test results on the Perth sand that was used for the centrifuge model tests at ETH Zurich: (a) $q_{\mathrm{cv}}-\varepsilon(\%)$ diagram, and (b) slope $M_{A C}$ of medium dense sample in the $p_{c v}^{\prime}-q_{c v}$ space (after Arnold, 2011; Buchheister, 2012; Nater, 2007) 
International Journal of Physical Modelling in Geotechnics Volume 18 Issue 6
Static and dynamic rocking stiffness

of shallow footings on sand:

centrifuge modelling

Taeseri, Laue, Martakis, Chatzi and

Anastasopoulos

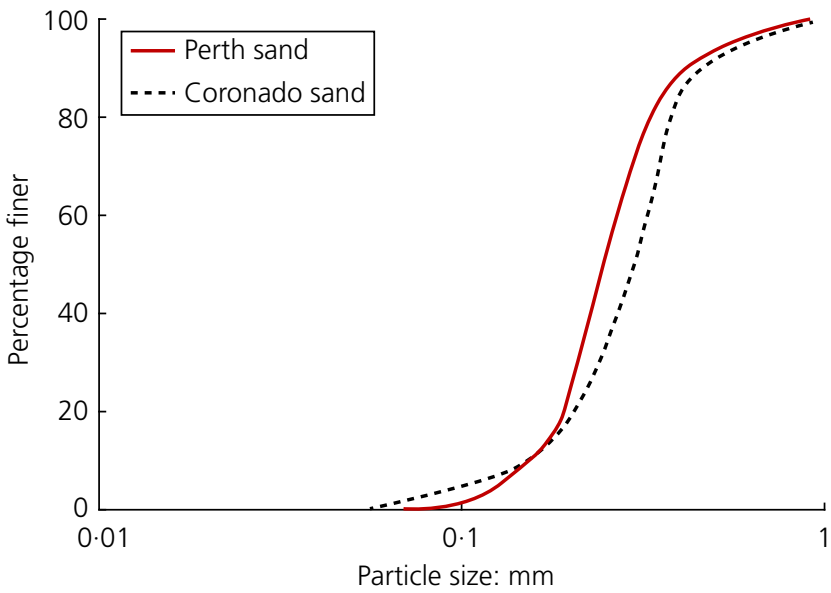

Figure 6. Grain size distribution of the Perth and Coronado Sand used for the physical model tests at ETH Zurich and UCSD, respectively (after Buchheister, 2012)

Table 4. Soil parameters of the Perth and Coronado sand

\begin{tabular}{lll} 
& Perth sand & $\begin{array}{l}\text { Coronado } \\
\text { sand }\end{array}$ \\
\hline USCS classification & $\mathrm{SP}$ & $\mathrm{SP}$ \\
Effective particle size, $D_{10}: \mathrm{mm}$ & $0 \cdot 14$ & $0 \cdot 12$ \\
Average particle size, $D_{50}: \mathrm{mm}$ & $0 \cdot 23$ & $0 \cdot 22$ \\
Uniformity coefficient, $C_{\mathrm{u}}$ & $1 \cdot 79$ & $1 \cdot 85$ \\
Coefficient of curvature, $C_{\mathrm{c}}$ & $1 \cdot 26$ & $1 \cdot 31$ \\
Specific density, $\rho_{\mathrm{s}}: \mathrm{kg} / \mathrm{m}^{3}$ & 2700 & 2680 \\
Dry density, $\rho_{\mathrm{d}}: \mathrm{kg} / \mathrm{m}^{3}$ & 1700 & 1695 \\
Density index $I_{\mathrm{d}}: \%$ & 80 & 80 \\
Void ratio, $e_{\min } \ldots e_{\max }$ & $0 \cdot 502 \ldots 0.752$ & - \\
Friction angle, $\phi_{\mathrm{c}}^{\prime}:{ }^{\circ}$ & 32 & 33 \\
Surface shear modulus, $G_{0}: \mathrm{kPa}$ & 35000 & 35000 \\
Surface shear wave velocity $V_{\mathrm{s}, 0}: \mathrm{m} / \mathrm{s}$ & 150 & 150 \\
& &
\end{tabular}

disc) into the strongbox. The pluviation height $h_{\mathrm{t}}$ and the diameter $d$ of the diffuser opening (i.e. the hole of the perforated disc) were found to be the most important variables to obtain the desired density.

Figure 7(b) illustrates the achieved dry density $\rho_{\mathrm{d}}$ as a function of pluviation height $h_{\mathrm{t}}$ and diffuser opening $d$ (Morales, 2015). The diffuser opening $d$ determines the depositional intensity $w\left(\mathrm{~g} /\left(\mathrm{min} / \mathrm{cm}^{2}\right)\right)$. As shown in Figure $7(\mathrm{~b})$, for a constant value of $h_{\mathrm{t}}$, an increase of $d$ leads to an increase of $w$, resulting in a decrease of $\rho_{\mathrm{d}}$. On the other hand, for a constant value of $w$, an increase of the pluviation height $h_{\mathrm{t}}$ leads to an increase of $\rho_{\mathrm{d}}$. The optimal combination, to achieve repeatability in reproducing a dense model of $\rho_{\mathrm{d}}=1.75 \mathrm{t} / \mathrm{m}^{3}$, was found to be a combination of relatively large pluviation height $h_{\mathrm{t}}=40 \mathrm{~cm}$ and diffuser opening $d=5 \mathrm{~mm}\left(w=16 \cdot 24 \mathrm{~g} /\left(\mathrm{min} / \mathrm{cm}^{2}\right)\right)$.
After pluviating the sand uniformly to the desired level, the foundation-structure model was positioned in the middle of the box. As sketched in Figure 7(a), in order to minimise boundary effects, the distance between the foundation and the lateral wall of the box was larger than $3 B$, and the distance between the foundation and the bottom of the box was kept larger than $2 B$ (Garnier et al., 2007). Nevertheless, the rocking mechanism is quite shallow and the distances of the order of $3 B$ to the lateral and $2 B$ to the bottom boundary were considered adequate in relative terms (Kokkali et al., 2014). Since the pluviation was performed outside the centrifuge at $1 \mathrm{~g}$, the strongbox had to be rotated by $90^{\circ}$ in order to be mounted onto the drum channel. This is a key disadvantage of the drum centrifuge, as compared against a beam centrifuge, where such rotation is taken care of by the centrifugal acceleration. In this case, some preventive measures had to be undertaken to prevent the sand from falling out of the container during rotation. Thus, the soil is saturated and consequently de-saturated, leading to a partially saturated sample. Since the Perth sand is fine sand, the soil matrix allows the formation of capillary forces, which lead to the development of suction (Morales, 2015). The latter offers an apparent cohesion of the order of $5 \mathrm{kPa}$, which is enough to keep the soil specimen under equilibrium for a short period of time until the centrifuge starts spinning. When the centrifuge reaches the desired $\boldsymbol{g}$-level, the minimal amount of water in the soil drains out of the system, and the apparent cohesion practically vanishes before the main test.

\section{In-flight measurement of the distribution of shear modulus with depth}

The main scope of the paper is the experimental measurement of static and dynamic small-strain stiffness. However, the derivation of meaningful results and insights calls for an accurate definition of the distribution of the shear modulus with depth. A two-step experimental procedure is adapted for this purpose, combining (a) measurement of shear wave velocity $V_{\mathrm{s} 0}$ and shear modulus $G_{0}$ at the ground surface, applying the SASW technique and $(b)$ estimation of the distribution of the shear modulus $G$ with depth on the basis of centrifuge shaking tests conducted at UCSD. The SASW method was only applied at the surface since the energy of the dynamic impact excitation tests conducted at ETH Zurich, was not sufficient to excite the soil column to an adequate depth. Therefore, the strength of the recorded signals did not allow the application of the SASW method for the estimation of the shear wave velocity with the depth.

\subsection{Estimation of shear modulus $G_{0}$ at the ground surface}

The shear wave velocity $V_{\mathrm{s} 0}$ and the shear modulus $G_{0}$ at the ground surface were measured by means of the SASW - spectral analysis of the surface waves method (Nazarian et al., 1983). 

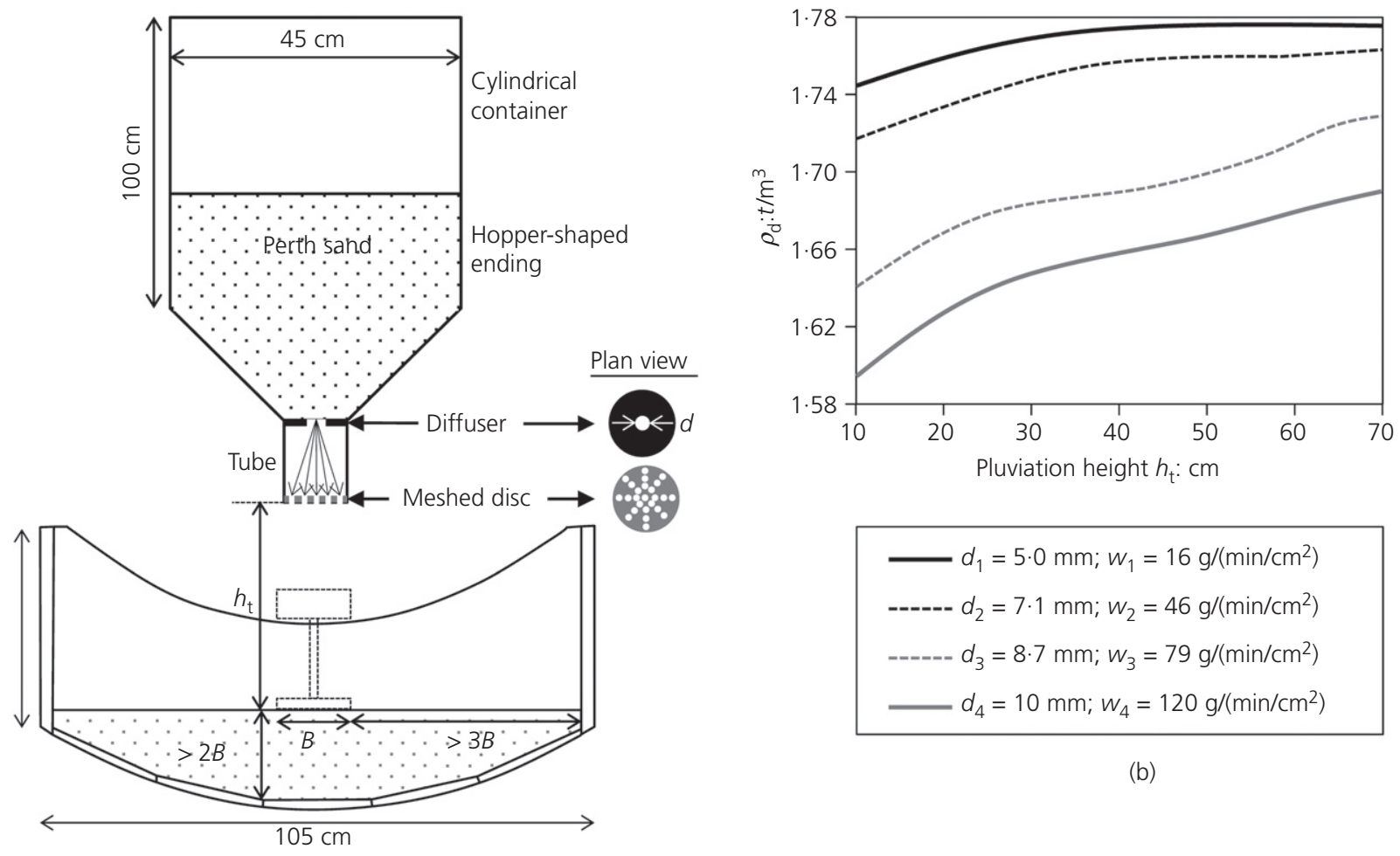

(a)

Figure 7. (a) Dry air pluviation apparatus employed for model preparation at ETH Zurich; and (b) soil density $\rho_{\mathrm{d}}$ as a function of pluviation height $h_{\mathrm{t}}$ and diffuser opening $d$ (after Morales, 2015).

For this purpose, additional centrifuge model tests were conducted at the geotechnical drum centrifuge of ETH Zurich. To apply the SASW method in the centrifuge, several issues had to be resolved: (a) generation of high-frequency acceleration, (b) sensors capable to capture high-frequency signals and $(c)$ the problem of wave reflections at model boundaries. Similar SASW measurements have earlier been conducted in the centrifuge by Siemer and Jessberger (1994), Siemer (1996) and Murillo et al. (2009), overcoming similar difficulties.

The centrifuge set-up for the SASW tests is illustrated in Figure 8 . The impulse excitation signal was generated by the impact of a spherical projectile shot against an aluminium plate $(2 \mathrm{~cm} \times 2 \mathrm{~cm} \times 0.2 \mathrm{~cm})$ located at the surface of a $10.8 \mathrm{~cm}(6.5 \mathrm{~m}$ in prototype scale at $60 \mathrm{~g})$. The tests were conducted at $60 \mathrm{~g}$, and the results and dimensions are discussed in model scale. The aluminium plate was armed with a Bruel $\&$ Kjaer accelerometer $\left(a_{0}\right)$, and three other similar accelerometers $\left(a_{1}, a_{2}, a_{3}\right)$ were installed at various distances from the impact source. Model preparation was identical to all other centrifuge model tests, with the cylindrical strongbox dry

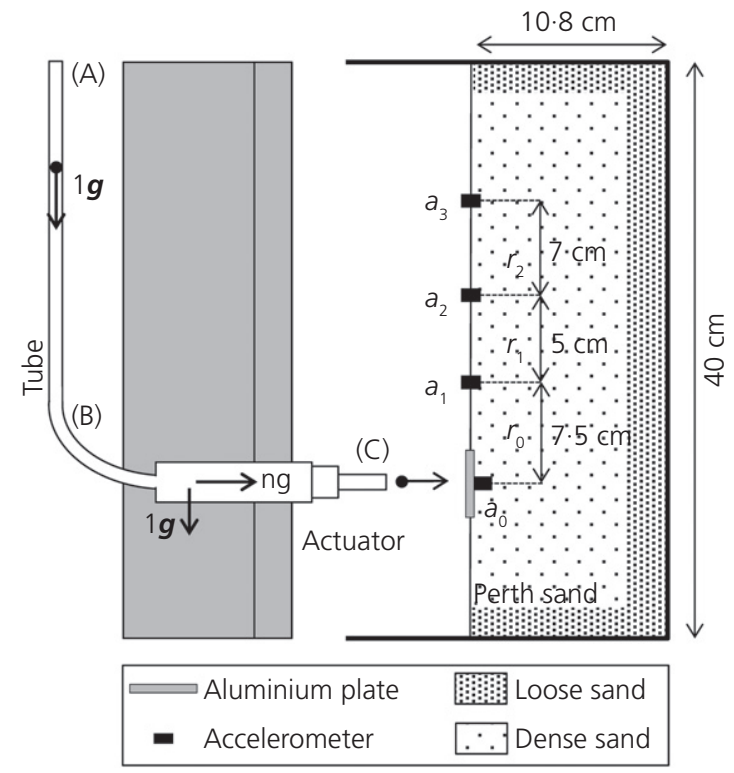

Figure 8. Centrifuge set-up for the in-flight SASW testing of Perth sand at ETH Zurich 
International Journal of Physical Modelling in Geotechnics Volume 18 Issue 6
Static and dynamic rocking stiffness

of shallow footings on sand:

centrifuge modelling

Taeseri, Laue, Martakis, Chatzi and

Anastasopoulos pluviated outside the centrifuge, partially saturated, rotated and installed onto the drum channel.

As previously discussed, one of the problems that had to be resolved is the generation of a high-frequency impulse excitation. Since the experiments are conducted at an enhanced gravitational level of $60 \mathrm{~g}$, the frequency has to be increased by $n=60$ (see scaling laws of Table 1). This implies that during the impact excitation, the contact time between the spherical projectile and the plate has to be reduced to a minimum. Studies conducted by Luong (1994) showed that the contact time between the projectile and the plate in the elastic regime can be controlled by changing the size and the mass of the projectile. Following this conclusion, several tests were conducted with different types of spherical projectiles, aiming to generate an 'elastic' impact excitation. The main variables were the diameter and the type of the projectile material. An elastic acceleration response signal was captured with a spherical projectile mass of $0.7 \mathrm{~g}$ and diameter of $3 \mathrm{~mm}$.

As shown in Figure 8 (all dimensions in model scale), the spherical projectile is dropped in the plastic tube at (A) from the stationary into the rotary environment, experiencing free fall under $1 \mathrm{~g}$ until reaching (B). Then, exposed to the horizontal centrifugal gravity of $n \mathrm{~g}$, it accelerates reaching (C) and finally the target (i.e. the aluminium plate) at a much higher end velocity. At (B), the tube is gently curved to minimise energy losses. At (C), the plastic tube is attached to an actuator able to move in all three directions. With the help of the on-board camera, the actuator is used to aim the projectile towards the centre of the $2 \mathrm{~cm} \times 2 \mathrm{~cm}$ square plate $\left(a_{0}\right)$. On impact onto the plate, a surface wave is generated, propagating (mostly) along the model surface. The receivers (accelerometers $a_{1}, a_{2}$ and $a_{3}$ ) capture the arriving surface wave. An example of this process is shown in Figure 9 (all dimensions in model scale). Figure 9(a) demonstrates the acceleration time histories at the three receivers, while their Fourier transforms are plotted in Figure 9(b). A fundamental frequency of about $1000 \mathrm{~Hz}$ was detected for all receivers. As it should be expected, the acceleration amplitude reduces with the distance from the source $\left(a_{0}\right)$. The delay in the arrival of the surface wave increases with distance, being maximised at the receiver $a_{3}$, which is the farthest. It should be noted that the measured acceleration time histories were filtered, following Buss and Lampach (2015).

In order to minimise parasitic boundary effects, particularly for the SASW experiments, lower density sand $\left(\rho_{\mathrm{d}, \text { Soft }}=\right.$ $1.5 \mathrm{t} / \mathrm{m}^{3}$ as opposed to $1.7 \mathrm{t} / \mathrm{m}^{3}$ of the rest of the model). In a way similar to Duxseal (Cheney et al., 1990), such a soft 'cushion' may partially absorb laterally propagating waves, reducing boundary effects. The receiver signals tend to confirm the efficiency of the applied method, as there is no visible disturbance that could be attributed to wave reflections at the lateral boundary. In addition, experiments were conducted with and without the low-density sand layer, and a reduction of the boundary-generated noise was clearly observed.

According to the conventional SASW technique, the time histories of two receivers, $a_{i}(t)$ and $a_{i+1}(t)$ are converted to the frequency domain, $A_{i}(f)$ and $A_{i+1}(f)$ by means of fast Fourier transform (FFT). The resulting phase difference $\Phi$ (Figure 9(c)) is also a function of frequency $f$

3. $\Phi_{i, i+1}=\arctan \left[\operatorname{Im}\left(G_{A_{i}, A_{i+1}}\right) / \operatorname{Re}\left(G_{A_{i}, A_{i+1}}\right)\right]$

where $G_{A_{i}, A_{i+1}}$ represents the cross-spectrum between signals $i$ and $i+1$, while $G_{A_{i}, A_{i}}$ is the power spectrum for each signal (Stokoe et al., 1994). Using the phase function, it is possible to calculate the travel time $t_{i, i+1}(f)$ for each frequency

4. $t_{i, i+1}(f)=\frac{\Phi_{i, i+1}(f)}{2 \pi f}$

The shear wave velocity close to the model surface $V_{\mathrm{s}, 0}$ is estimated knowing the distances between the receivers

5. $\quad V_{\mathrm{s}, 0}=\frac{\left(d_{i+1}-d_{i}\right)}{t_{i, i+1}(f)}$

This procedure can be applied for any pair of receivers. The small-strain shear modulus at the ground surface $G_{\max , 0}$ can then be calculated as follows

\section{6. $G_{\mathrm{max}, 0}=v_{\mathrm{s}, 0}^{2} \cdot \rho_{\mathrm{d}}$}

With $\rho_{\mathrm{d}}=1.7 \mathrm{t} / \mathrm{m}^{3}$, the SASW measurements produce $V_{\mathrm{s}, 0} \approx$ $140 \mathrm{~m} / \mathrm{s}$ and $G_{\max , 0} \approx 35 \mathrm{MPa}$.

\subsection{Distribution of the shear modulus with depth $G_{\max }(z)$}

The previously discussed SASW measurements are very useful, but provide no information on the distribution of the shear modulus with depth $G_{\max }(z)$. As shown by Gazetas (1991b), the distribution of $G_{\max }$ is a key parameter for the stiffness of shallow and embedded foundations. According to Gazetas (1991b), a general expression of $G_{\max }(z)$ for inhomogeneous half-space can be defined as

7. $G_{\max }(z)=G_{\max , 0}\left(1+\frac{\alpha}{b} z\right)^{n}$

where $G_{\max , 0}$ is the small-strain shear modulus at the ground surface, $\alpha$ the parameter obtained by curve fitting to the 


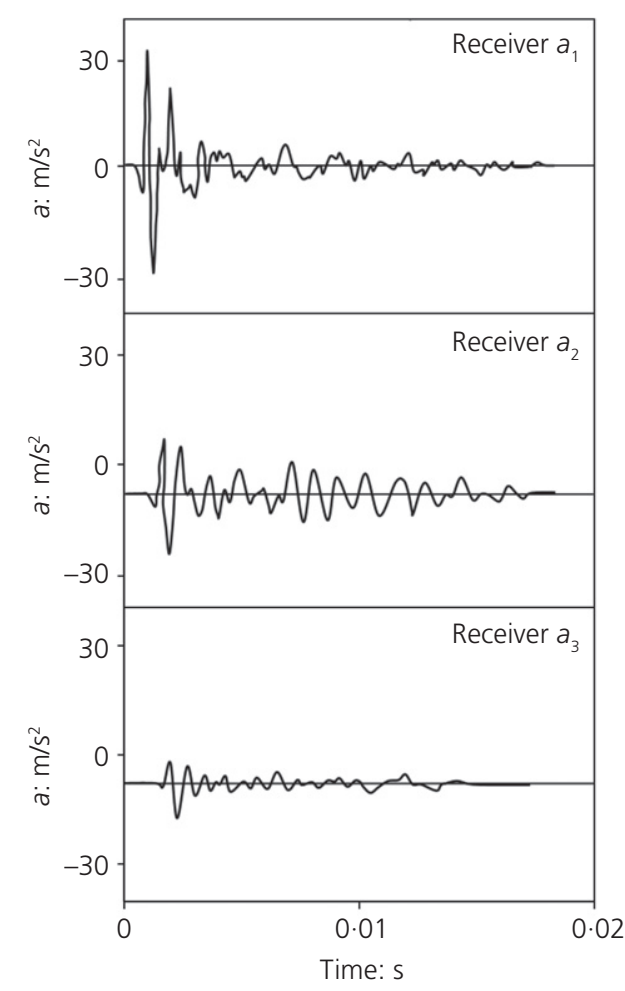

(a)

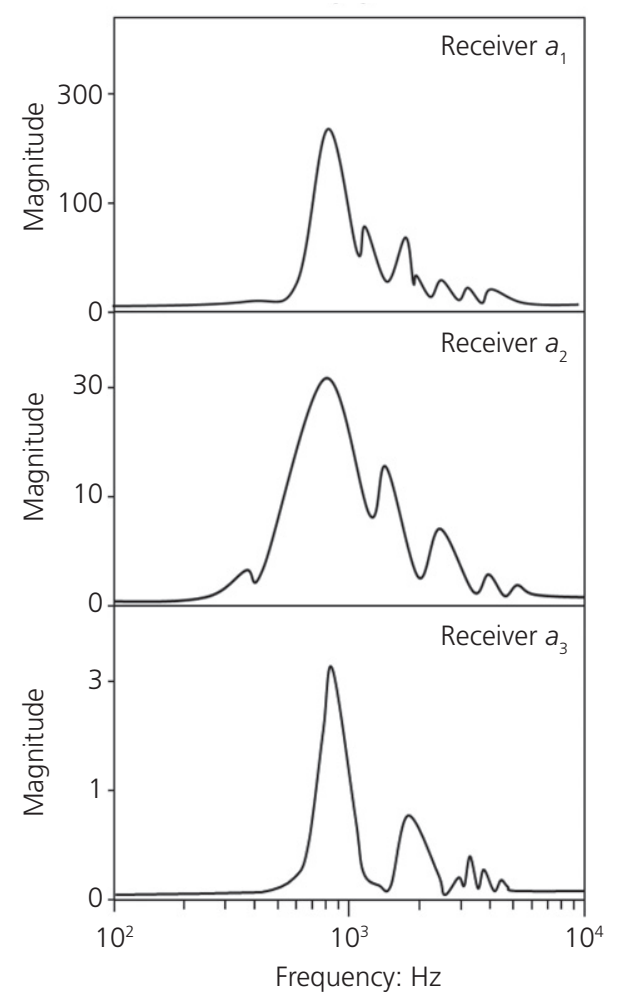

(b)

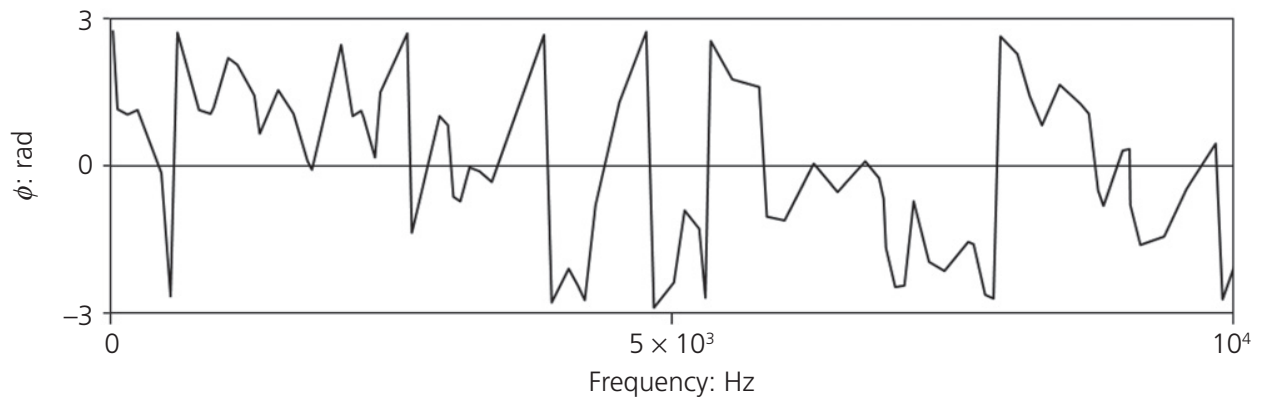

(c)

Figure 9. Typical results of in-flight SASW measurements: (a) acceleration time histories at receivers $a_{1}, a_{2}$ and $a_{3}$; (b) corresponding Fourier spectra; and (c) phase difference spectrum between receivers $a_{1}$ and $a_{2}$

experimental results, $b$ is the half of the width of a square footing and $n$ the exponent, generally assumed $0 \cdot 5$ for sands.

Based on the SASW measurements, $G_{\max , 0}$ is known, but there is no information on $\alpha$. To determine $\alpha$, the shaking experiments conducted at UCSD are used. Constructed by Actidyn, the $4 \mathrm{~m}$ diameter UCSD beam centrifuge can reach a maximum centrifugal acceleration of $130 \mathrm{~g}$. It is equipped with servo-hydraulic centrifuge-mounted (PVL Technologies' ES-9) shaker. For the shaking tests conducted at UCSD, a rigid $(35.6 \mathrm{~cm} \times 35.6 \mathrm{~cm} \times 24.8 \mathrm{~cm})$ container was used, but its lateral walls were coated with a foam-type material, allowing soil deformation relative to the rigid boundary and partially absorbing incoming waves.

Several shaking experiments were conducted on a $6.5 \mathrm{~m}$ thick Coronado sand layer. The model preparation and sand densities were kept as similar as possible to the ETH Zurich centrifuge tests. As shown in Figure 6 and Table 4, the Coronado sand was deliberately chosen to comprise similar granular properties and 
International Journal of Physical Modelling in Geotechnics Volume 18 Issue 6
Static and dynamic rocking stiffness

of shallow footings on sand:

centrifuge modelling

Taeseri, Laue, Martakis, Chatzi and

Anastasopoulos grain size distribution to Perth sand. The image analysis carried out with the environmental scanning electron microscope (ESEM) showed that the grain shape of the Perth sand is rounded (Buchheister, 2012). Unfortunately, the Coronado sand is not as well documented. However, its constitution and origins (Coronado beach) suggested that it should also be of similar angularity. The similarity between the two sands is further confirmed by the measured small-strain shear modulus at the ground surface $G_{\max , 0}$, which as discussed in the next paragraphs, was found to be quite similar. As sketched in Figure 10, four PCB Piezotronics (352M54) accelerometers $\left(a_{1}-a_{4}\right)$ were installed at different heights $\left(z_{1}-z_{4}\right)$. The input motion was varied using a Hanning window (Testa et al., 2004), albeit for the analysis presented herein, only the first six cycles of the response signal are taken into consideration in order to focus on soil behaviour at very small strains.

For each accelerometer $a_{i}(i=1-4)$, the horizontal displacement $u_{i}$ is estimated by means of double integration of the corresponding acceleration $a_{i}$ with the assumption of zero displacement, velocity and acceleration as initial conditions (Yang et al., 2006)

8. $\quad u_{i}(t)=\iint a_{i}(t) \mathrm{d} t \mathrm{~d} t$

This allows for definition of the average shear strain $\gamma_{i, i+1}(t)$ between accelerometers $i$ and $i+1$

9. $\quad \gamma_{i, i+1}(t)=\frac{u_{i}(t)-u_{i+1}(t)}{z_{i}-z_{i+1}}$
Zeghal and Elgamal (1994) proposed a formula to derive the shear stress $\tau\left(z_{i, i+1}\right)$ at mid-depth $\left(z_{i}+z_{i+1}\right) / 2$ between the accelerometers, using the measured acceleration time histories $i$ and $i+1$

10. $\tau\left(z_{i, i+1}\right)=\int_{z_{i}}^{z_{i+1}} \rho a(t) \mathrm{d} z \cong \frac{1}{2} \rho z\left(a_{i}(t)+a_{i+1}(t)\right)$

A linear interpolation of the shear stress $\tau\left(z_{i, i+1}\right)$ is assumed between $z_{i}$ and $z_{i+1}$. A fourth-degree polynomial equation was also considered for the fitting of the experimentally obtained lateral displacement $u_{i}(t)$. Its derivative was taken and multiplied by 2 in order to obtain the shear strain $\gamma_{i}(t)$. The results were then compared with the simpler method proposed by Zeghal and Elgamal (1994) and the differences were less than $5 \%$. The reliability of the simpler method has also been demonstrated by various researchers (Holzer and Youd, 2007; Koga and Matsuo, 1990; Zeghal et al., 1996).

Figure 11 summarises the procedure and its results. The derived $\tau-\gamma$ loops between $a_{i}$ and $a_{i+1}$ are depicted in Figure 11(a), focusing on the quasi-elastic regime of the shear strain $0 \cdot 005 \%<\gamma<0 \cdot 01 \%$. Based on these loops, the shear modulus $G_{i, i+1}$ can be calculated (Seed et al., 1986)

\section{1. $G=\frac{\tau}{\gamma}$}

The derived $G_{i, i+1}$ at different depths $z_{i, i+1}$ and confining pressure $\sigma_{0}\left(z_{i, i+1}\right)$, on the basis of the $\tau-\gamma$ loops, is a secant shear modulus (Figure 11(b)). Each of the derived $G_{i, i+1}$

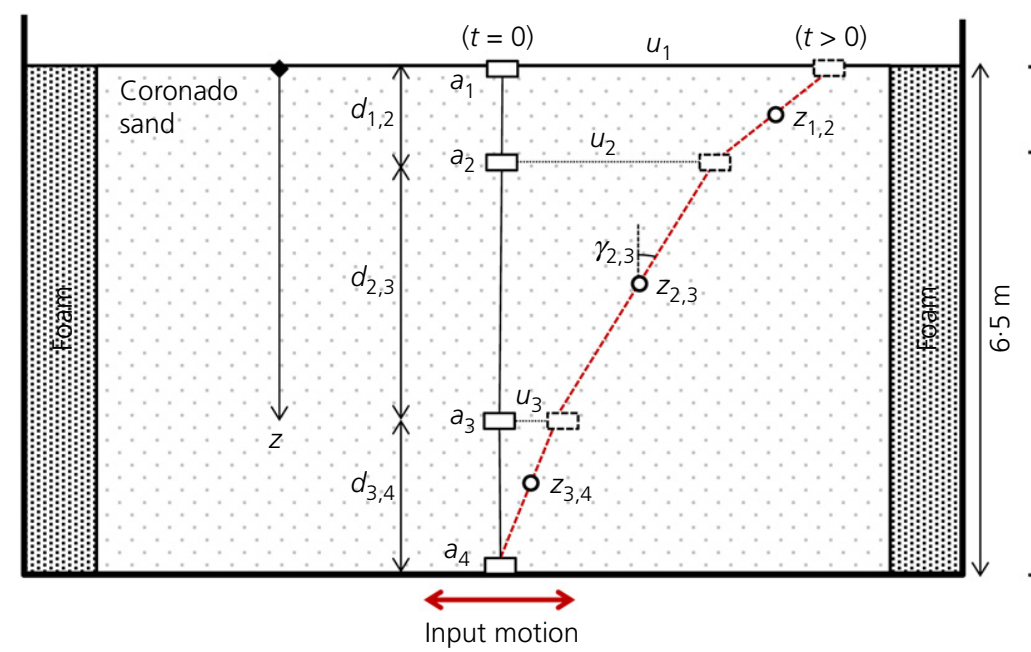

\begin{tabular}{|c|c|c|c|}
\hline i & $z_{i}: m$ & $z_{i, i+1}: m$ & $d_{i, i+1}: m$ \\
\hline \multirow[t]{2}{*}{1} & 0 & & \\
\hline & & -0.75 & 1.5 \\
\hline \multirow[t]{2}{*}{2} & $-1 \cdot 5$ & & \\
\hline & & -3 & 3 \\
\hline \multirow[t]{2}{*}{3} & $-4 \cdot 5$ & & \\
\hline & & $-5 \cdot 5$ & 2 \\
\hline 4 & $-6 \cdot 5$ & & \\
\hline
\end{tabular}

Figure 10. Determination of the shear modulus on the basis of centrifuge shaking table tests conducted at the geotechnical beam centrifuge of UCSD: sensor locations and notation. 

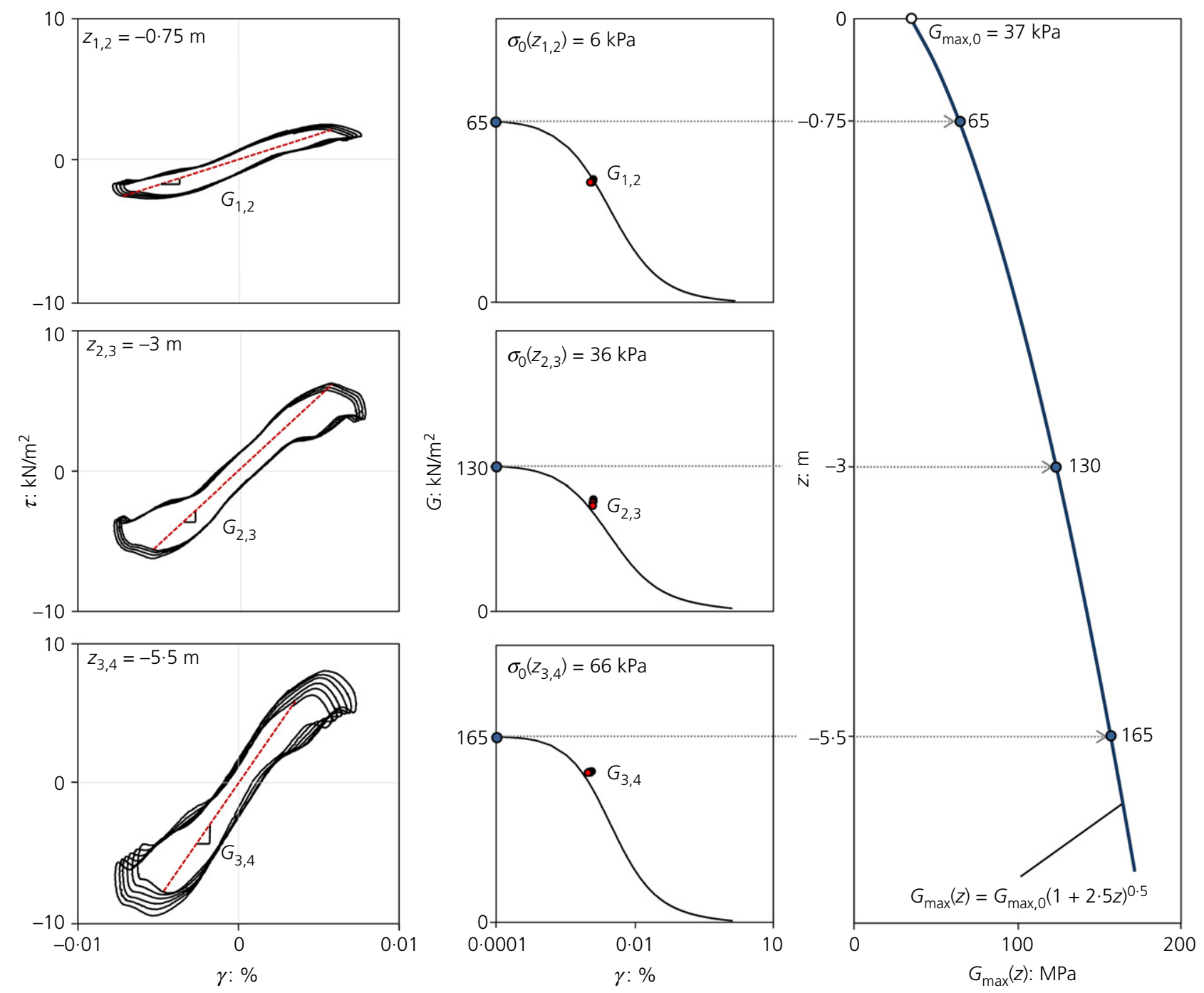

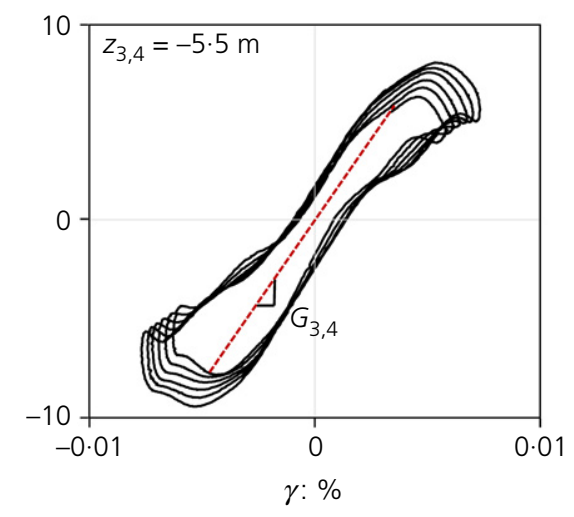

(a)

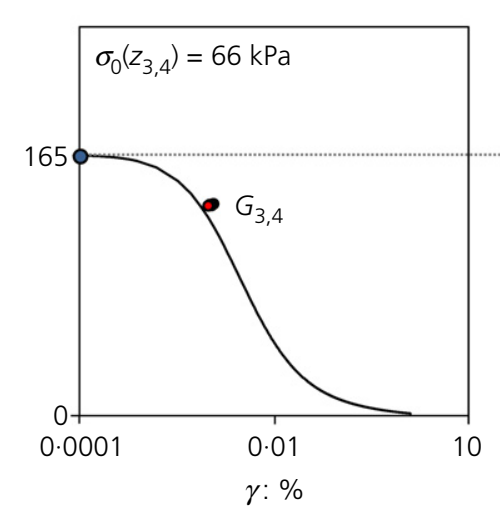

(b)

(c)

Figure 11. Determination of the shear modulus on the basis of centrifuge shaking table tests conducted at the geotechnical beam centrifuge of UCSD: (a) measured $\tau-\gamma$ loops; (b) fitting of $G-\gamma$ curves on the basis of the measurements; and (c) back calculation of distribution of $G_{\max }$ with the depth

corresponds to a specific shear strain $\gamma$, which is very small but not zero. Therefore, for each depth, the small-strain shear modulus $G_{\max (i, i+1)}$ is estimated by fitting a hyperbolic regression curve for the degradation of the shear modulus with shear strain $\gamma$ (Ishibashi and Zhang, 1993), depending on the confining pressure $\sigma_{0}\left(z_{i, i+1}\right)$ of the soil (Figure 11(b)).

Figure 11(c) illustrates the derived distribution of the smallstrain shear modulus with depth $G_{\max }(z)$, and its approximation with the parabolic distribution (Equation 7) proposed by Gazetas (1991b) with $\alpha / b=2 \cdot 5(1 / m)$. With the assumption of a parabolic distribution of the shear modulus with depth, the value of the shear modulus at the surface $G_{\max , 0}$ for the Coronado sand is $37 \mathrm{MPa}$, which compares very well to the one obtained with the SASW technique for the Perth sand of the ETH Zurich experiments (35 MPa). This further confirms the strong similarities between the two sands. Therefore, the derived distribution of shear modulus with depth, $G_{\max }(z)=$ $G_{\text {max }, 0}(1+2 \cdot 5 z)^{0 \cdot 5}$, may be considered transferable to the Perth sand used for the centrifuge model tests conducted at ETH Zurich. At this point, it should be stated that the above parameters could have been determined by fitting the experimentally measured profile $G_{\max }(z)$ by a power function on the basis of the least-squares regression technique, instead of 
International Journal of Physical Modelling in Geotechnics Volume 18 Issue 6
Static and dynamic rocking stiffness

of shallow footings on sand:

centrifuge modelling

Taeseri, Laue, Martakis, Chatzi and

Anastasopoulos assuming $n=0 \cdot 5$. Such a technique actually leads to $n=0 \cdot 48$. However, since the very common assumption of $n=0.5$ offered very good results (differences of $<2 \%$ ), it is considered a reasonable simplification.

\section{Monotonic pushover tests}

This section describes the experimental set-up and key results of monotonic pushover tests, conducted at the ETH Zurich drum centrifuge. The experimental results are used to derive static small-strain rocking stiffness of the examined footings. The latter is compared with the widely used analytical solutions of formulation of Gazetas (1991b).

\subsection{Experimental set-up for monotonic pushover tests}

The experimental set-up and instrumentation for the monotonic pushover tests is summarised in Figure 12. To maximise the distance to model boundaries, a specially designed semi-circular container was used for these experiments. Its curvature follows that of the drum channel at the bottom, rendering a soil model of $105 \mathrm{~cm}$ total length. A Concens (con35) electric actuator of $2 \cdot 2 \mathrm{kN}$ capacity, equipped with high-resolution force transducers (MTS, Type 8523), was employed to conduct lateral displacement-controlled monotonic pushover tests. The load cell has a maximal capacity of $2 \mathrm{kN}$ and a precision of $0.011 \%$. The range of speed of the actuator varies from 1.44 to $4.5 \mathrm{~mm} / \mathrm{s}$ and the stroke can extend up to $135 \mathrm{~mm}$. The actuator is connected to the model with a special hinged connection, which allows unconstrained rotation and vertical displacement of the model relative to the actuator (sliding within the joint is allowed in the vertical sense). The rate of deformation (i.e. velocity) was kept constant at $1.44 \mathrm{~mm} / \mathrm{s}$. Given the scale of the experiments, this corresponds to very slow quasi-static loading.

As shown in Figure 12, two laser displacement transducers ( $L_{1}$ and $L_{2}$, Micro-Epsilon, optoNCDT 1402) were used to measure the lateral displacement of the model, and to compute the rotation $\theta$ as described in the sequel. The measurement is based on the triangulation principle (Micro-Epsilon, 1997). The lasers have a measurement range of $200 \mathrm{~mm}$ and a resolution of $0.04 \mathrm{~mm}$. The monotonic experiments were recorded at a sampling rate of $100(1 / \mathrm{s})$. The sensitivity of the lasers and the load cells allowed capturing the response of the system at very small strains.

The model preparation was conducted outside the drum, following the previously described partial saturation process. Taking advantage of the developing apparent cohesion, the sand is kept under equilibrium until spinning. When the desired g-level is reached, the minimal amount of water in the soil drains out, and the apparent cohesion practically vanishes. During the process of installation to the drum channel, the foundation-structure was rigidly fixed to the strongbox by a provisory bar. After mounting of the strongbox onto the drum channel, the actuator was connected to the structure (keeping it in place), and the provisory bar was finally removed.

The main focus of the study is to experimentally measure the small-strain rotational stiffness $K_{\mathrm{r}}$ of shallow footings

$$
\text { 12. } k_{\mathrm{r}}=\frac{M}{\theta}
$$

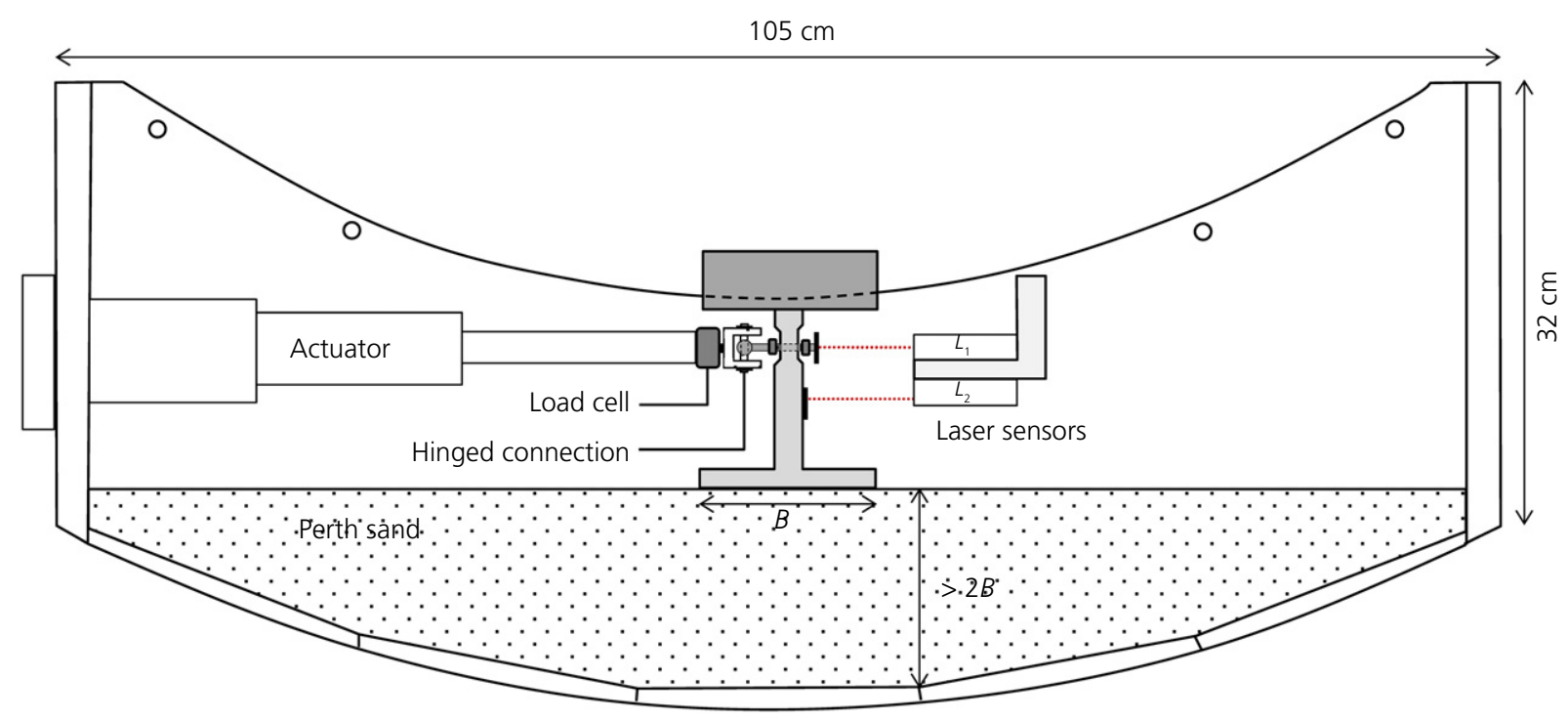

Figure 12. Test set-up for monotonic pushover tests conducted at the ETH Zurich geotechnical drum centrifuge (dimensions in model scale) 
International Journal of Physical Modelling in Geotechnics Volume 18 Issue 6
Static and dynamic rocking stiffness

of shallow footings on sand:

centrifuge modelling

Taeseri, Laue, Martakis, Chatzi and

Anastasopoulos where $M$ is the overturning moment and $\theta$ the rotation. The laser transducers measured the lateral displacement at two different points ( $L_{1}$ and $L_{2}$ in Figure 13). With the simplifying (but reasonable assumption) of a rigid superstructure, the rotation can be calculated as

$$
\text { 13. } \theta=\frac{u_{L_{1}}-u_{L_{2}}}{h_{L}}
$$

where $u_{L 1}$ and $u_{L 2}$ are the lateral displacements measured at $L_{1}$ and $L_{2}$, respectively, and $h_{L}$ is the vertical distance between the two measuring points. The horizontal force acting on the system is equal to the actuator force $F_{\text {act }}$, and the latter is used to compute the overturning moment $M$

14. $H=F_{\text {act }}$

15. $M=H \cdot h_{\mathrm{cg}, 1}$

where $h_{\mathrm{cg}, 1}$ is the distance between the bottom of the foundation and the actuator. The vertical load of each structure is

16. $V=m_{\mathrm{tot}} \cdot \boldsymbol{g}$

where $m_{\text {tot }}$ is the total mass of the foundation-structure model. Since the present study focuses on small-strain response, second-order $(P-\delta)$ effects can be neglected.

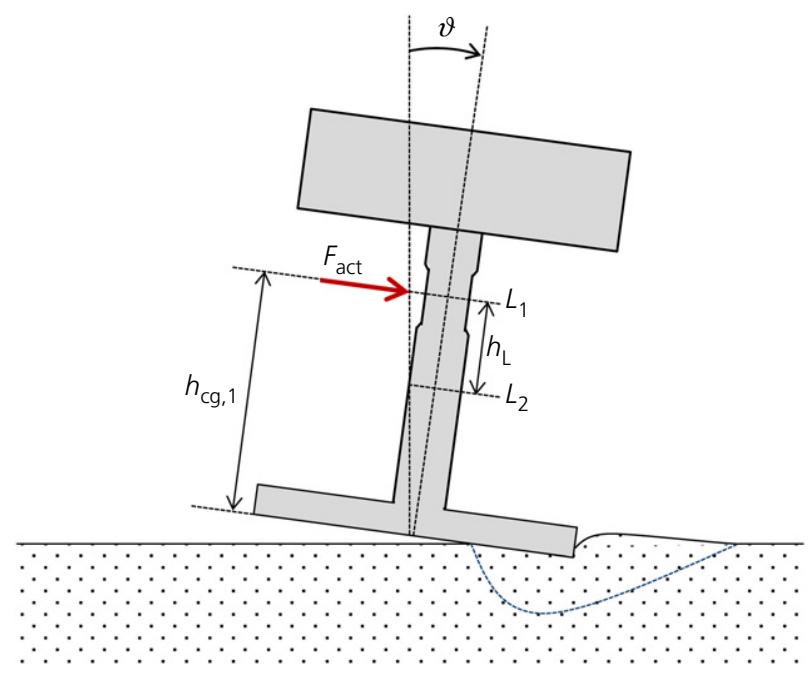

Figure 13. Calculation of $M-\theta$ response for the monotonic pushover tests on the basis of actuator force $F_{\text {act }}$ (load cell) and measured lateral displacements (laser sensors)

\subsection{Results of monotonic pushover tests and comparison with existing solutions}

The results of the monotonic lateral pushover tests on eight different physical models (models 1-8, Table 2), conducted at the ETH Zurich drum centrifuge at $60 \mathrm{~g}$ and $100 \mathrm{~g}$ are presented in this chapter. The rocking stiffness is defined as the tangent stiffness for rotation $\theta \leq 0.0005 \mathrm{rad}$. In this range of $\theta$, the rocking stiffness was found to be almost constant. It could therefore be considered as the quasi-elastic small-strain stiffness. A more rigorous method was also considered for the estimation of the small-strain rocking stiffness. A function was fitted to the experimental loading curve, and its first derivative was then calculated for $\theta=0$. The difference between the two methods was found to be negligible (of the order of $2 \%$ or less).

According to the widely used analytical solution of Gazetas (1991b), the static rocking stiffness of a massless surface foundation lying on inhomogeneous half-space is

$$
\text { 17. } K_{\mathrm{r}, \text { Static }}=\frac{3 \cdot 6}{1-v} G_{0, \max } b^{3}\left(1+\frac{1}{3} \alpha\right)^{n}
$$

The above formulation refers to pure rocking motion (swaying is prohibited).

As discussed by Gazetas et al. (2013) and Anastasopoulos and Kontoroupi (2014), the initial small-strain rocking stiffness $K_{\mathrm{r} \text { Static }}$ is largely affected by the factor of safety against static loading $F_{\mathrm{s}}$. The latter has been shown to decrease with the increase of $F_{\mathrm{s}}$, due to the unavoidable non-linearities induced in the soil by the vertical load. Since Equation 17 does not account for such initial non-linearities, and the solution presented by Gazetas et al. (2013) refers to clayey soil, only tests with relatively large $F_{\mathrm{s}} \geq 10$ are used for comparison.

The first four tests are selected for this purpose. The results of the pushover tests are summarised in Figure 14 in terms of moment-rotation $(M-\theta)$ response. In all cases examined, the measured small-strain stiffness $K_{\mathrm{r} \text {,Static }}$ compares very well to the analytical solution of Gazetas (1991b). Although the experimental measurement of $K_{\mathrm{r} \text {,Static }}$ is the main goal of this paper, the pushover tests also provide information on the ultimate moment capacity $M_{\text {ult }}$ of the shallow foundations examined. The measured $M_{\text {ult }}$ is compared with the widely used expression proposed by Gajan et al. (2005)

$$
\text { 18. } M_{\mathrm{ult}}=\operatorname{Mgb}\left(1-\frac{1}{F_{\mathrm{s}}}\right)
$$

As also summarised in Table 5, the experimental measurements of tests 1-4 are in very good agreement with the previously mentioned expressions, both in terms of $K_{\mathrm{r} \text {,Static }}$ and 


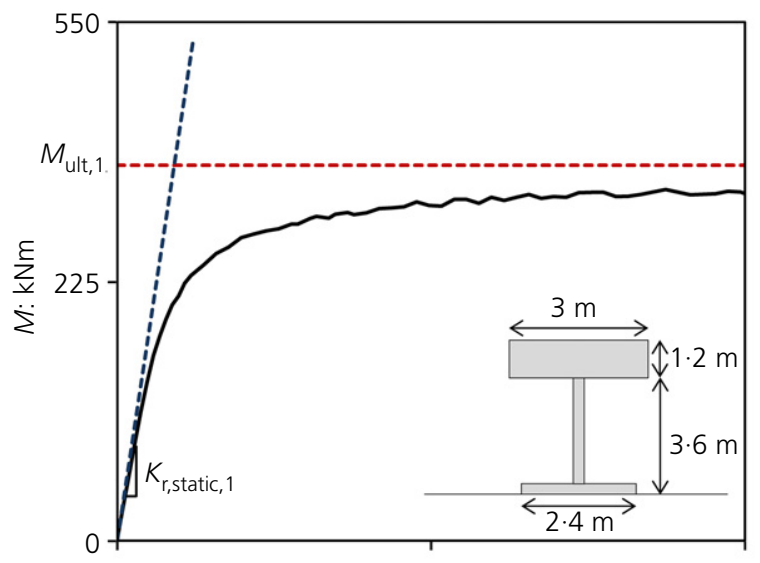

(a)

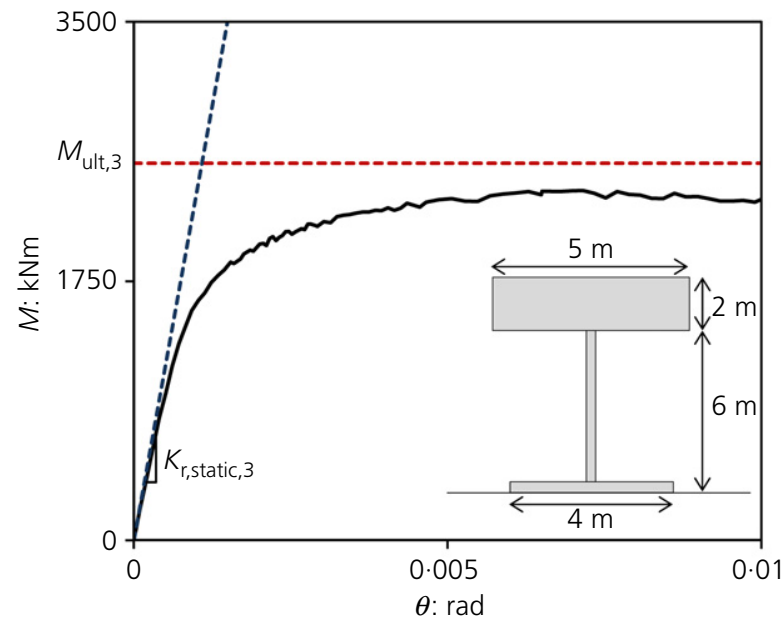

(c)

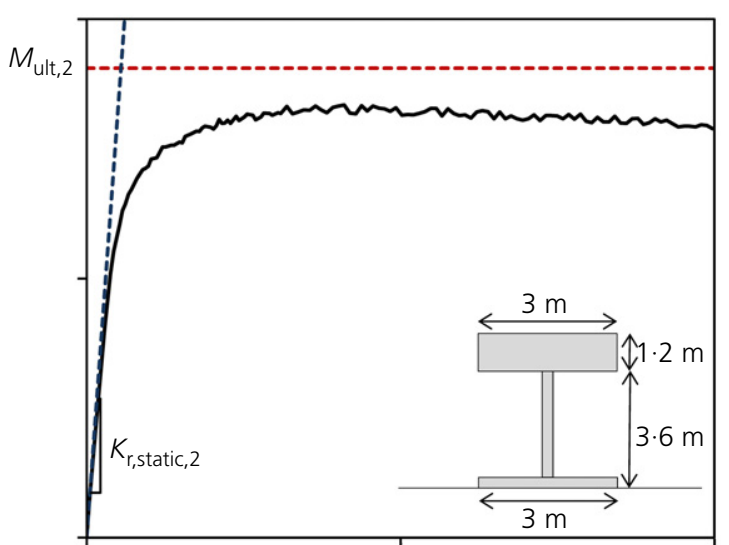

(b)

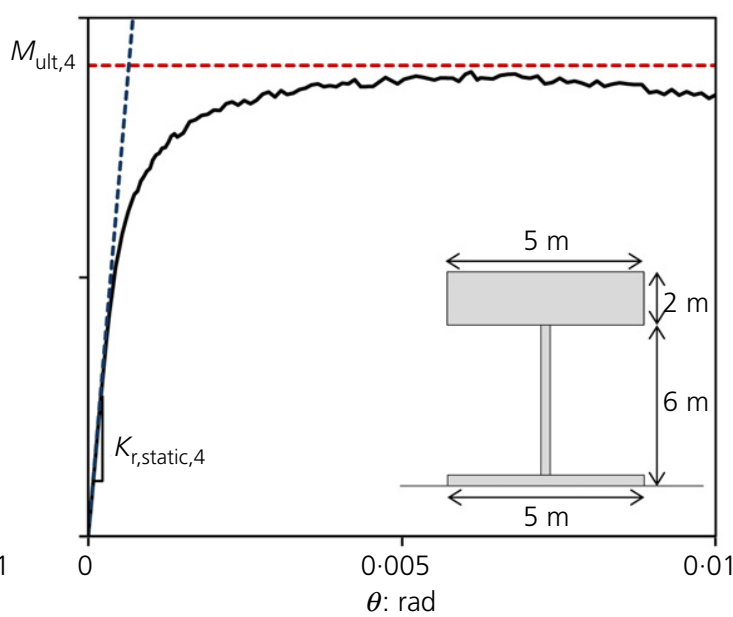

(d)

Figure 14. Moment-rotation $(M-\theta)$ response from monotonic pushover tests and comparison with small-strain static stiffness $K_{\mathrm{r} \text {,static }}$ according to Gazetas (1991b) and ultimate moment capacity $M_{\text {ult }}$ based on Gajan et al. (2005): (a) test 1: $F_{\mathrm{s}}=12$; (b) test 2: $F_{\mathrm{s}}=23$; (c) test 3: $F_{\mathrm{s}}=15$; and $(\mathrm{d})$ test 4: $F_{\mathrm{s}}=29$

Table 5. Static small-strain rocking stiffness $K_{r \text {,static }}$ and moment capacity $M_{\text {ult }}$ obtained through the monotonic pushover tests, and comparison with the solutions proposed by Gazetas (1991b) and Gajan et al. (2005), respectively

\begin{tabular}{|c|c|c|c|c|c|c|}
\hline $\begin{array}{l}\text { Model } \\
\text { ID }\end{array}$ & $\begin{array}{c}\boldsymbol{F}_{\mathbf{s}}: \\
\text { dimensionless }\end{array}$ & $\begin{array}{l}\text { Mult tests: } \\
\text { kNm }\end{array}$ & $\begin{array}{l}\text { Mult Equation 18: } \\
\text { kNm }\end{array}$ & $\begin{array}{l}K_{\mathrm{r}, \text { static }} \text { tests: } \\
\text { MNm }\end{array}$ & $\begin{array}{c}K_{\mathrm{r}, \text { static }} \text { Equation 17: } \\
\text { MNm }\end{array}$ & $\begin{array}{l}\text { Differential static stiffnesses } \\
\text { Equation } 17 \text { against tests: \% }\end{array}$ \\
\hline 1 & 12 & 369 & 398 & 406 & 439 & 8 \\
\hline 2 & 23 & 458 & 498 & 864 & 911 & 5 \\
\hline 3 & 15 & 2333 & 2540 & 2260 & 2351 & 4 \\
\hline 4 & 29 & 3059 & 3180 & 4792 & 4938 & 3 \\
\hline 5 & 4 & 1034 & 1137 & 373 & 439 & 16 \\
\hline 6 & 8 & 1377 & 1422 & 840 & 911 & 8 \\
\hline 7 & 5 & 7010 & 7261 & 2076 & 2351 & 14 \\
\hline 8 & 10 & 8905 & 9076 & 4391 & 4938 & 12 \\
\hline
\end{tabular}


International Journal of Physical Modelling in Geotechnics Volume 18 Issue 6
Static and dynamic rocking stiffness

of shallow footings on sand:

centrifuge modelling

Taeseri, Laue, Martakis, Chatzi and

Anastasopoulos
$M_{\text {ult }}$. On the other hand, with the decrease of the safety factor for tests 5-8 $\left(F_{\mathrm{s}}<10\right)$, the differences between the theoretically estimated $K_{\mathrm{r}, \text { Static }}$ and the experimentally measured become larger. The ultimate moment capacity does not seem to be affected by the safety factor and the values for tests 5-8 are also in good agreement with the theoretical values.

\section{Dynamic impulse excitation tests}

This section deals with the dynamic impulse excitation. After discussing the experimental set-up, key test results are presented and compared with the existing solutions.

\subsection{Experimental set-up for impact excitation tests}

The dynamic impulse loading is applied by discharging spherical projectiles at the head of the structure. The experimental set-up is similar to the SASW tests, with the main difference lying in the target. The projectiles were made of steel, with a diameter of $3 \mathrm{~mm}$ and a weight of $0.7 \mathrm{~g}$. The model preparation is summarised in Figure 15. As for the previous tests, the model was pluviated outside the centrifuge (Figure 15(a)), but this time a cylindrical strongbox of $40 \mathrm{~cm}$ diameter and $20 \mathrm{~cm}$ height was used (Figure 2(a)). After installing the structure (Figure 15(b)) and the sensors, the previously discussed partial saturation process was employed to maintain equilibrium until spinning, and a magnetic actuator was used to keep the structure in place during installation (Figure 15(c)). The model was subsequently rotated by $90^{\circ}$ and installed onto the drum channel (Figure 15(d)). After reaching the desired $\boldsymbol{g}$-level, the magnetic actuator was released (Figure 15(e)), and the test was conducted by discharging the spherical projectiles through a $5 \mathrm{~mm}$ diameter tube employing the same methodology as for the SASW tests (Figure 15(e)). The lateral distance between the foundation and the cylindrical wall of the box is larger than $3 B$ and the vertical distance between the footing and the bottom of the box was kept larger than $2 B$. Nevertheless, the rocking mechanism is quite shallow and the distance of the order of $3 B$ to the lateral boundary is considered adequate in relative terms (Kokkali et al., 2014).

Preliminary sensitivity tests conducted by Martakis (2016) and Martakis et al. (2016) showed that wave reflections at model boundaries are indeed negligible. This is due to the type (impulse) and intensity of the dynamic excitation, combined with the previously discussed absorbing layer of looser sand,

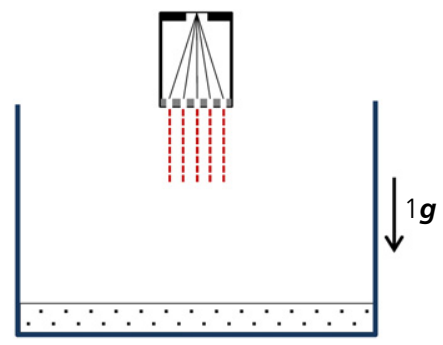

(a)

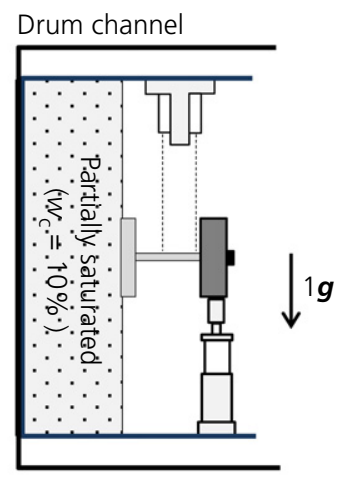

(d)

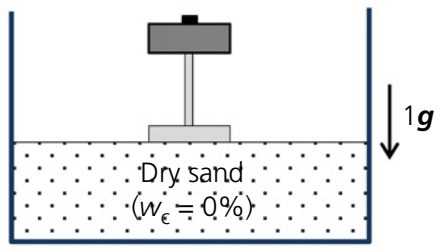

(b)

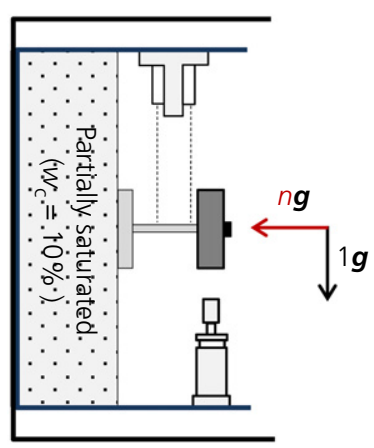

(e)

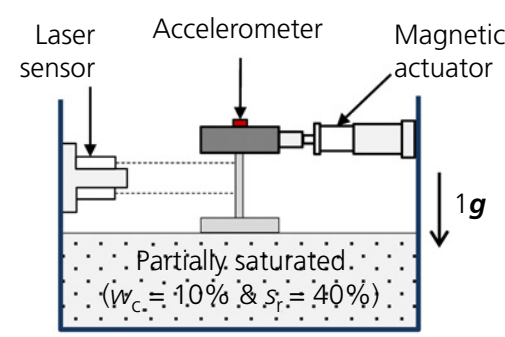

(c)

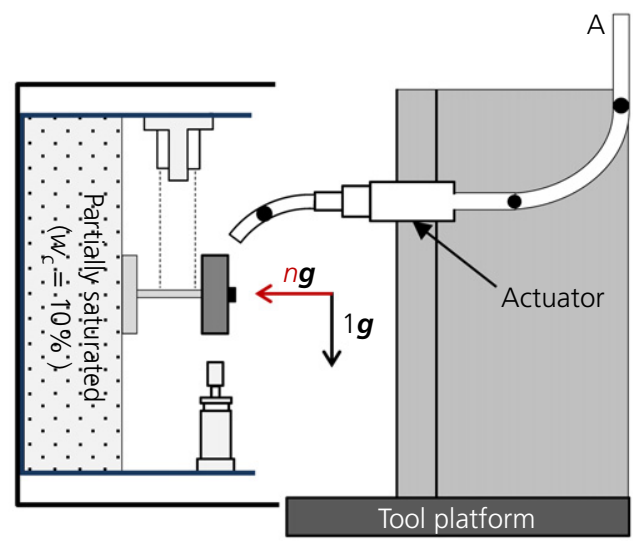

(f)

Figure 15. Model preparation for dynamic tests conducted at ETH Zurich: (a) dry sand pluviation outside the centrifuge; (b) structure installation; (c) saturation and subsequent desaturation, installation of laser sensors and magnetic actuator; (d) rotation of the model by $90^{\circ}$ and installation on the drum channel; (e) spinning up to the desired $\boldsymbol{g}$-level and deactivation of the magnetic support; and ( $\mathrm{f}$ ) impact excitation generated by the release of spherical projectiles against the head of the structure 
International Journal of Physical Modelling in Geotechnics Volume 18 Issue 6
Static and dynamic rocking stiffness

of shallow footings on sand:

centrifuge modelling

Taeseri, Laue, Martakis, Chatzi and

Anastasopoulos which was applied at the bottom and lateral boundaries of the strongbox. The instrumentation is also similar to the previous tests, with the main difference being the installation of a miniature uniaxial Bruel \& Kjaer accelerometer at the head of the structure (Figure 16). The measured acceleration $a$ is used to compute the inertial force, under the assumption that the mass of the column is negligible compared with the mass of the head of the structure $m_{\text {Top }}(<5 \%$ on average)

19. $H=m_{\text {Top }} \cdot a$

The overturning moment can then be computed as follows

20. $M=H \cdot h_{\mathrm{cg}, 2}$

where $h_{\mathrm{cg}, 2}$ is the distance between the bottom of the foundation and the centre of mass of the head of the structure.

\subsection{Results of impact excitation tests and comparisons with existing solutions}

The impact of the spherical projectile at the head of the structure initially leads to transient vibration, followed by free vibration. Figure 17 shows an exemplary derivation of the natural frequencies of the soil-foundation-structure system, referring to test $4\left(F_{\mathrm{S}}=29\right)$. The recorded acceleration time history at the top of the structure is shown in Figure 17(a), unfiltered and filtered. The transient phase of response is evident at the beginning of

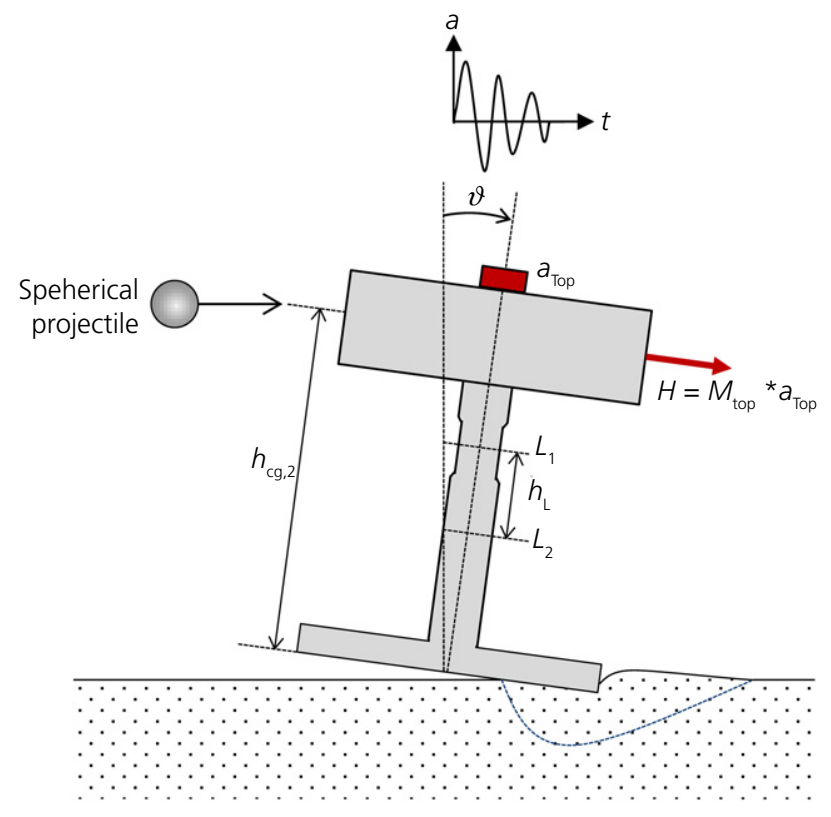

Figure 16. Calculation of $M-\theta$ response for the dynamic tests on the basis of measured acceleration (head of structure) and lateral displacements (laser sensors) the record, followed by free vibration, and attenuation of the motion due to material damping.

The power spectral density of the unfiltered signal is depicted in Figure 17(b). The first four dominant natural frequencies are directly identifiable at $3 \cdot 8,23,34$ and $43 \mathrm{~Hz}$. The first peak (at $3.8 \mathrm{~Hz}$ ) has a significantly higher amplitude; it represents the coupled rocking-swaying mode of the soilfoundation-structure system. Since this first mode is the dominant one and most relevant for the purposes of this study, a low-pass Butterworth filter with Nyquist frequency of $12 \mathrm{~Hz}$ was subsequently applied (Selesnick and Burrus, 1998) to eliminate the noise generated by the centrifuge and the instrumentation, and to isolate the predominant rocking frequency.

Using Equations 12 and 19, the moment-rotation $(M-\theta)$ loops of Figure 18 can be computed. In all four cases, the large loop corresponds to the transient phase of the response, just after impact of the spherical projectile. During the subsequent cycles of free vibration, the $M-\theta$ response is clearly more elastic, with the secant being markedly higher. Hence, the dynamic small-strain rocking stiffness $K_{\mathrm{r}, \mathrm{Dyn}}$ is measured at the time at which the hysteresis loops diminish, as this effectively corresponds to quasi-elastic response of the slightly overloaded system that is assumed to still be in the elastic range. The results are compared with the analytical solution of Gazetas (1991b) for the estimation of the dynamic rocking stiffness of a square surface foundation lying on inhomogeneous half-space

$$
\text { 21. } K_{\mathrm{r}, \text { Dyn }}=K_{\mathrm{r}, \text { Static }}\left(1-0 \cdot 2 a_{0}\right)
$$

where $K_{\mathrm{r}, \mathrm{Static}}$ is the static small-strain rocking stiffness, $a_{0}=\omega_{\mathrm{n}} B / V_{\mathrm{s} 0}$ is the dimensionless frequency of the system, $\omega_{\mathrm{n}}$ the angular frequency, $V_{\mathrm{s} 0}$ the shear wave velocity at the surface.

As previously discussed, the shear wave velocity at the model surface $V_{\text {So }}$ was measured through the SASW centrifuge model tests. The angular frequency $\omega_{\mathrm{n}}$ is defined by Gazetas (1991b) as the vibration frequency of a massless machine foundation lying on inhomogeneous half-space. However, in this study, the excitation is not due to steady-state dynamic loading for example due to a shaker or machine vibration. Instead, the 'steady-state' response here is the free vibration of the system. Therefore, $\omega_{\mathrm{n}}$ is assumed equal to the natural angular frequency $\omega_{\mathrm{n}}=2 \pi f_{\mathrm{n}}$ of the free vibrating soil-foundation-structure system. The first (and dominant) mode of response, and therefore $\omega_{n}$ can be estimated using the Fourier spectrum of the recorded acceleration, which is computed by FFT. The resulting spectra for tests 1-4 are shown in Figure 19, and a summary for all tests is given in Table 6 . 


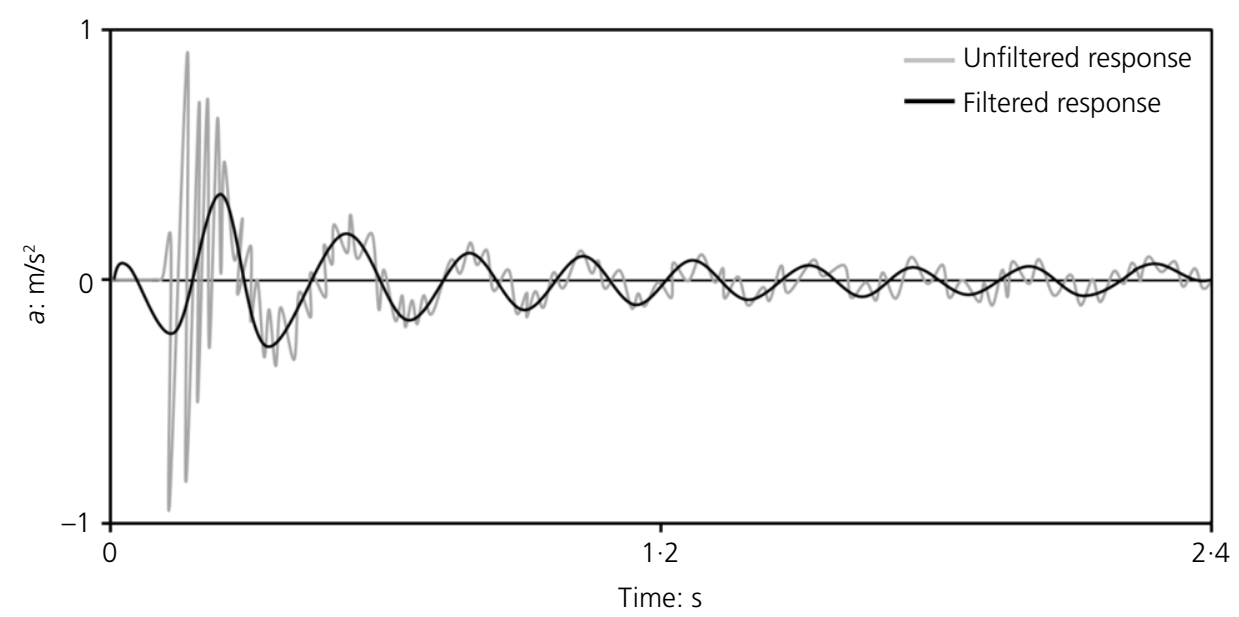

(a)

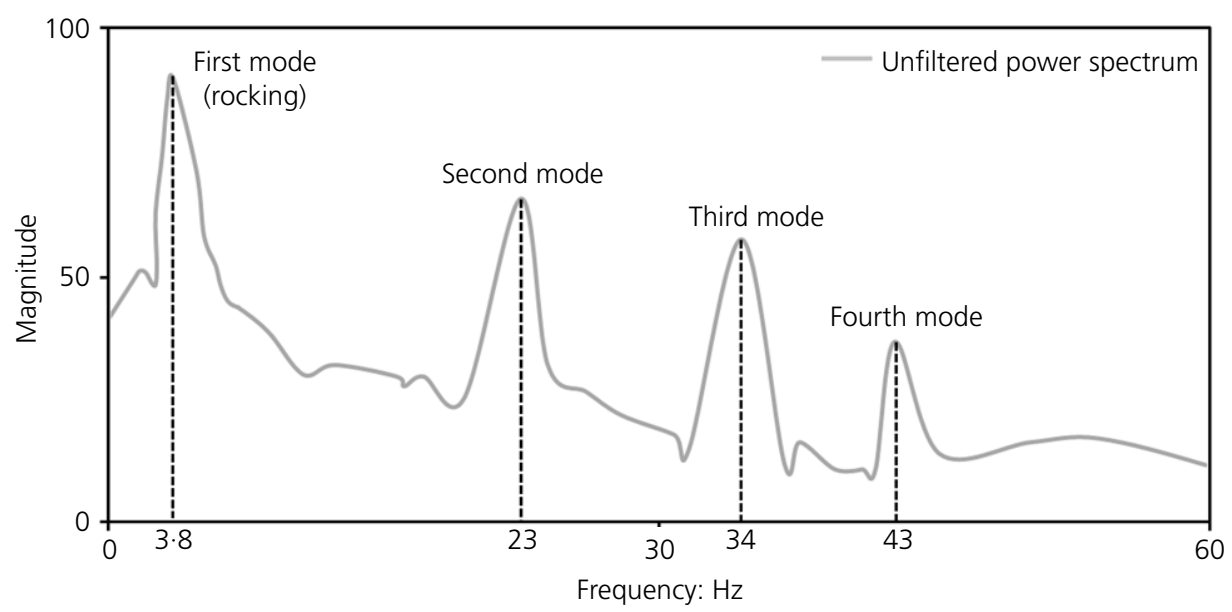

(b)

Figure 17. Derivation of natural frequencies on the basis of the dynamic centrifuge tests (results shown for test $4, F_{s}=29$ ): $(a)$ measured acceleration time history at structure head; and (b) unfiltered power spectal density, used to derive the natural frequencies

Table 6 further compares the experimentally derived dynamic small-strain rocking stiffness values to the analytical solution of Gazetas (1991b), obtained using Equation 21. For all cases examined (tests 1-8), the experimental measurements are in very good agreement to the analytical solution, with the differences not exceeding $10 \%$. Given the various simplifying assumptions and the unavoidable differences in boundary conditions (half-space conditions are not experimentally possible), this is considered an excellent result.

\section{Dynamic against static rocking stiffness}

In this work, two different types of centrifuge testing methods have been applied to measure the small-strain rocking stiffness of shallow foundations on sand. A comparison between the two different methods is considered of interest. Figure 20 compares the moment-rotation $(M-\theta)$ response of models 2 and 3 subjected to static pushover and dynamic impulse loading. Evidently, the maximum foundation moment during dynamic loading is much smaller than the moment capacity $M_{\text {ult }}$ of the foundation. This observation is in support of the hypothesis that the dynamic impulse tests induced quasi-elastic loading to the soil-foundationstructure system. However, zooming into the results for small angles of rotation (right-handside of Figure 20) reveals a hysteretic response even for rotation $\theta<0.0003$ (the same conclusion is drawn looking at the previously discussed Figure 18).

The comparison shown in Figure 20 indicates that the measured dynamic rocking stiffness $K_{\mathrm{r}, \mathrm{Dyn}}$ is slightly smaller than the static rocking stiffness $K_{\mathrm{r} \text {,Static }}$ During dynamic excitation, a small portion of the input energy is dissipated due 
International Journal of Physical Modelling in Geotechnics Volume 18 Issue 6
Static and dynamic rocking stiffness

of shallow footings on sand:

centrifuge modelling

Taeseri, Laue, Martakis, Chatzi and

Anastasopoulos

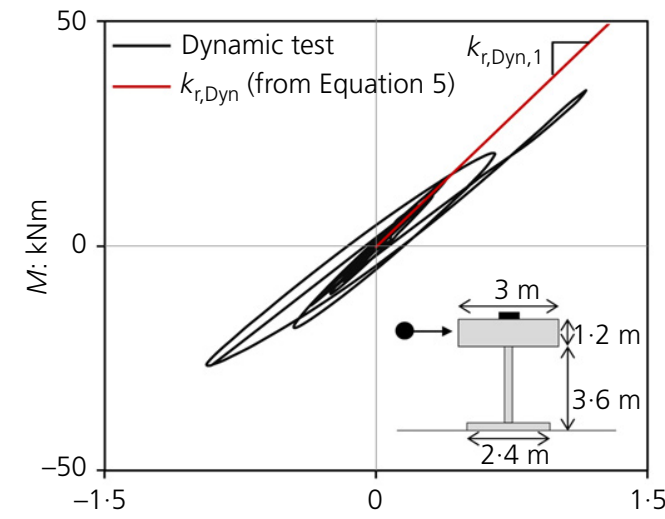

(a)

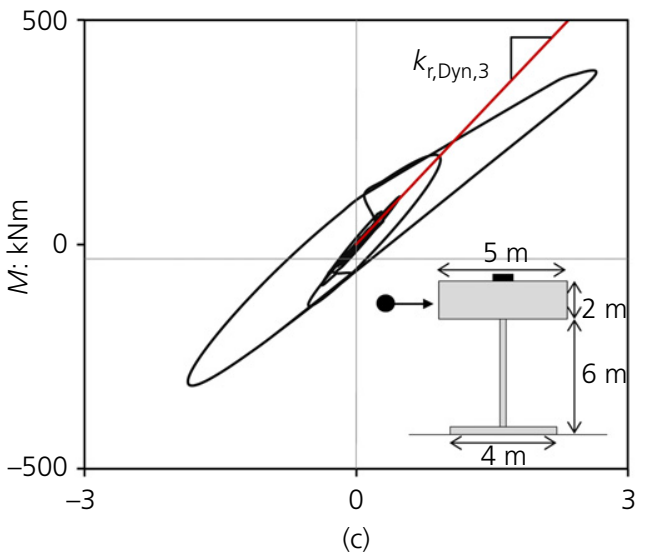

$\theta: \operatorname{rad} \times 10^{-4}$

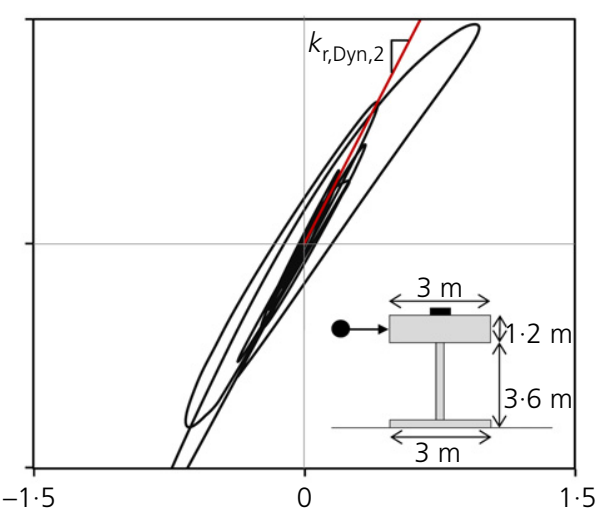

(b)

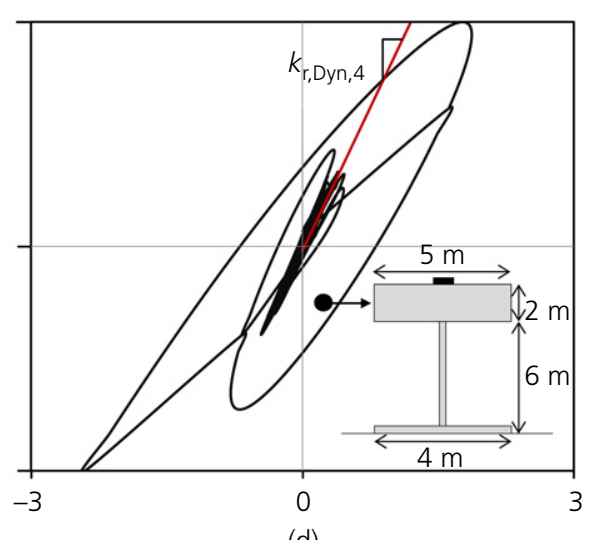

(d)

$\theta: \operatorname{rad} \times 10^{-4}$

Figure 18. Moment-rotation $(M-\theta)$ response from dynamic impact excitation tests and comparison with small-strain dynamic stiffness $K_{\mathrm{r}, \text { Dyn }}$ according to Gazetas (1991b): (a) test 1: $F_{\mathrm{s}}=12$; (b) test 2: $F_{\mathrm{s}}=23$; (c) test 3: $F_{\mathrm{s}}=15$; and (d) test 4: $F_{\mathrm{s}}=29$

to material and radiation damping. Although radiation damping cannot be reproduced in the centrifuge model tests (due to the presence of container boundaries), the difference is close to what would theoretically be expected. Table 7 compares the experimentally measured static $\left(K_{\mathrm{r}, \mathrm{static}}\right)$ and dynamic $\left(K_{\mathrm{r}, \text { Dyn }}\right)$ small-strain rocking stiffness, and the ratio $\left(K_{\mathrm{r}, \text { Dyn }} / K_{\mathrm{r}, \text { static }}\right)$ to the their theoretical ratio $\left(1-0 \cdot 2 a_{0}\right)$, according to Gazetas (1991b). For all cases examined, the ratio $K_{\mathrm{r} \text {,Dyn }} / K_{\mathrm{r} \text {,static }}$ is in very good agreement with the theoretical one. On average, $K_{\mathrm{r} \text {,Dyn }} / K_{\mathrm{r} \text {,static }}$ is of the order of 0.92 . This relatively small relation between the dynamic to the static stiffness is due to the relatively low value of the dimensionless frequency $a_{0}$ of the soil-foundation-structure system. As revealed by Equation 21, the decrease of $a_{0}$ leads to an increase of the ratio $K_{\mathrm{r}, \mathrm{Dyn}} / K_{\mathrm{r} \text {,static }}$, which means that the dynamic response is similar to its static response.

As shown in Figure 21, Dobry and Gazetas (1986) showed that an increase of the dimensionless frequency $a_{0}=\omega_{\mathrm{n}} B / V_{\mathrm{s}}$ considerably reduces the ratio $K_{\mathrm{r}, \mathrm{Dyn}} / K_{\mathrm{r} \text {,static. The latter is }}$ calculated for the conducted experiments, and plotted in comparison with Dobry and Gazetas (1986) in the same diagram. The experimentally derived ratios are in good agreement with the theoretical ones for $a_{0}<1$ and $K_{r \text {,Dyn }} / K_{r \text {,static }} \cong 1$, plotting a little lower for all cases examined. The observed discrepancies can be attributed to the simplifying assumption regarding $a_{0}$, and the fact that the response of the physical model was not $100 \%$ linear. As previously discussed, during impact of the spherical projectile, the $M-\theta$ loops show some limited hysteresis of higher amplitude. Although only the free vibration is considered for the estimation of $K_{\mathrm{r}, \mathrm{Dyn}}$, the impact has already induced a limited amount of non-linearity in the soil.

Overall, the experimental measurements are in good agreement with widely used solutions and previous research on the subject. In terms of small-strain static and dynamic rocking stiffnesses, the centrifuge models conducted herein fully 


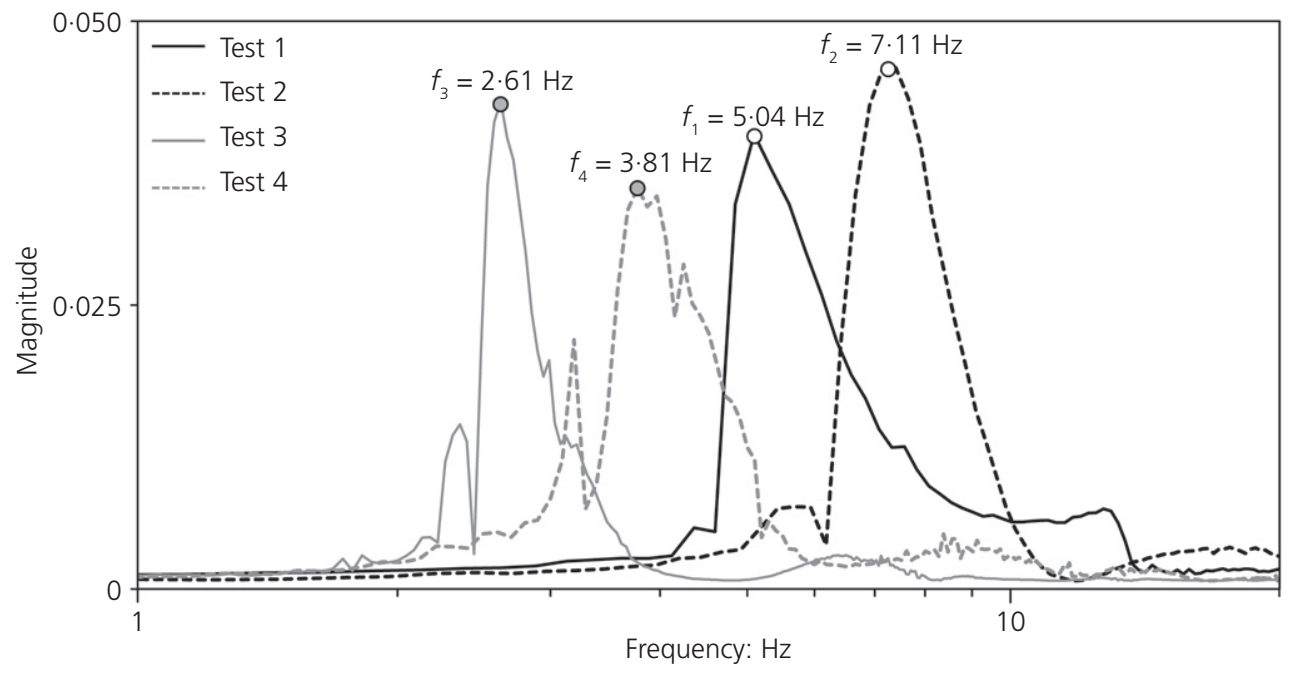

Figure 19. Derivation of natural frequencies of the soil-foundation-structure system on the basis of impact excitation centrifuge model tests conducted at ETH Zurich (tests 1-4 with $F_{\mathrm{s}}$ between 12 and 29)

Table 6. Comparison of measured dynamic small-strain rocking stiffnesses to the solution of Gazetas (1991b), Equation 21

\begin{tabular}{|c|c|c|c|c|c|c|}
\hline $\begin{array}{l}\text { Model } \\
\text { ID }\end{array}$ & $\begin{array}{c}F_{s}: \\
\text { dimensionless }\end{array}$ & $\begin{array}{l}K_{\mathrm{r}, \text { Dynamic }} \\
\text { tests: } \mathrm{MNm}\end{array}$ & $\begin{array}{l}f_{n}: \\
\mathrm{Hz}\end{array}$ & $\begin{array}{c}\left(1-0.2 a_{0}\right) \text { Equation 21: } \\
\text { dimensionless }\end{array}$ & $\begin{array}{c}K_{\mathrm{r}, \text { Dynamic }} \text { Equation } \\
\text { 21: } \mathrm{MNm}\end{array}$ & $\begin{array}{c}\text { Difference Equation } 21 \\
\text { against tests: \% }\end{array}$ \\
\hline 1 & 12 & 389 & 5.04 & 0.95 & 416 & 6 \\
\hline 2 & 23 & 775 & $7 \cdot 11$ & 0.90 & 824 & 6 \\
\hline 3 & 15 & 2131 & $2 \cdot 61$ & 0.95 & 2240 & 5 \\
\hline 4 & 29 & 4340 & $3 \cdot 81$ & 0.92 & 4516 & 4 \\
\hline 5 & 4 & 366 & $3 \cdot 14$ & 0.93 & 421 & 13 \\
\hline 6 & 8 & 748 & $4 \cdot 81$ & 0.87 & 840 & 11 \\
\hline 7 & 5 & 1947 & $1 \cdot 21$ & 0.96 & 2264 & 14 \\
\hline 8 & 10 & 3921 & $2 \cdot 51$ & 0.89 & 4614 & 15 \\
\hline
\end{tabular}

confirm the formulas proposed by Dobry and Gazetas (1986) and Gazetas (1991b). This good comparison with analytical solutions can also be seen as a confirmation of the validity of the experimental procedure when applied to more complex scenarios. This is of particular importance, as the latter is employed to experimentally measure stiffnesses and capacities of various embedded foundations on level and inclined ground, for which analytical solutions hardly exist.

\section{Conclusions}

The work presented herein forms part of a meticulous experimental campaign, studying the seismic performance of shallow and embedded foundations on level and inclined soil. The work overviews monotonic and cyclic pushover tests, and dynamic impulse excitation tests, conducted at the ETH Zurich drum centrifuge; as well as dynamic seismic shaking tests, conducted at the UCSD beam centrifuge used here to identify the distribution of small-strain stiffness with depth. The present paper focuses on the development of a centrifuge modelling technique, combining static and dynamic impulse testing for experimental measurement of the small-strain rocking stiffness of shallow foundations in sand. To allow for derivation of meaningful insights, a novel two-step experimental procedure for in-flight measurement of the distribution of shear modulus with depth was developed. The latter combines measurement of the shear modulus $G_{0}$ at the ground surface employing the SASW technique, with estimation of the distribution of shear modulus $G$ with depth using acceleration measurements of shaking table tests.

Dynamic loading is considered as the most challenging part of the work presented herein. In contrast to beam centrifuges (such as the one of UCSD), dynamic loading is restricted to impact loadings in drum centrifuge (Chikatamarla et al., 2006; Kapogianni et al., 2016). A novel centrifuge-mounted tubeactuator was developed and employed to discharge spherical projectiles in-flight against the head of SDOF models lying on different shallow foundations on sand. This technique allowed generating dynamic impulse excitation, which was used to 
International Journal of Physical Modelling in Geotechnics Volume 18 Issue 6
Static and dynamic rocking stiffness

of shallow footings on sand:

centrifuge modelling

Taeseri, Laue, Martakis, Chatzi and

Anastasopoulos

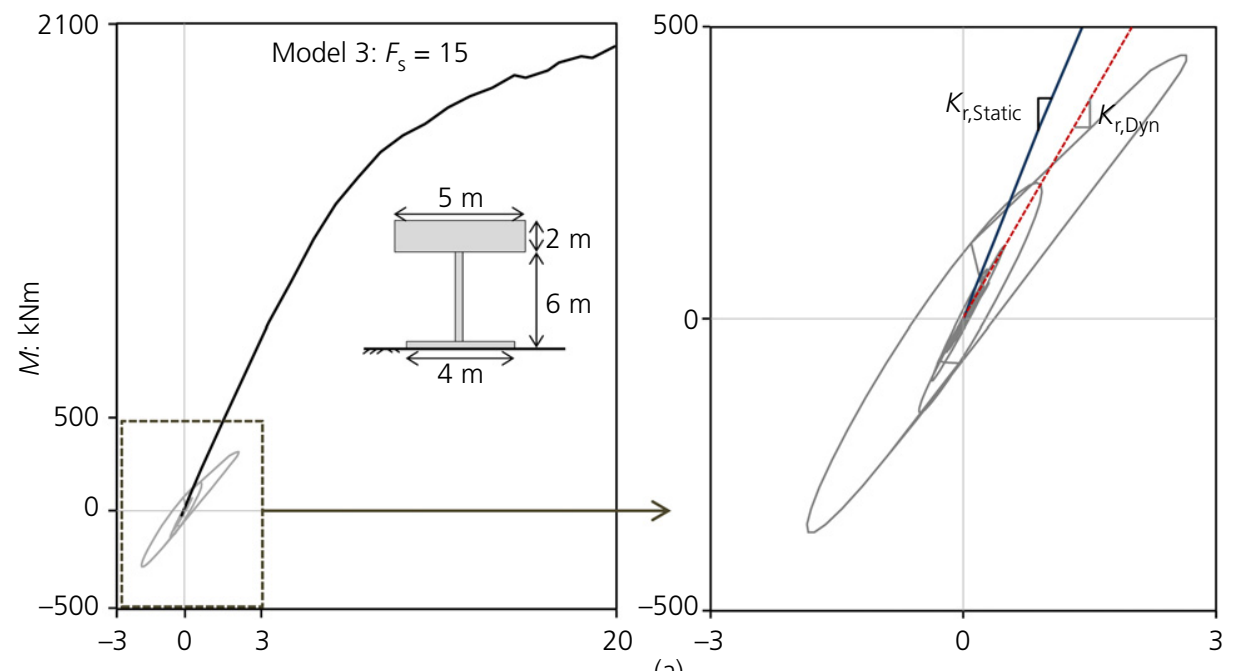

(a)

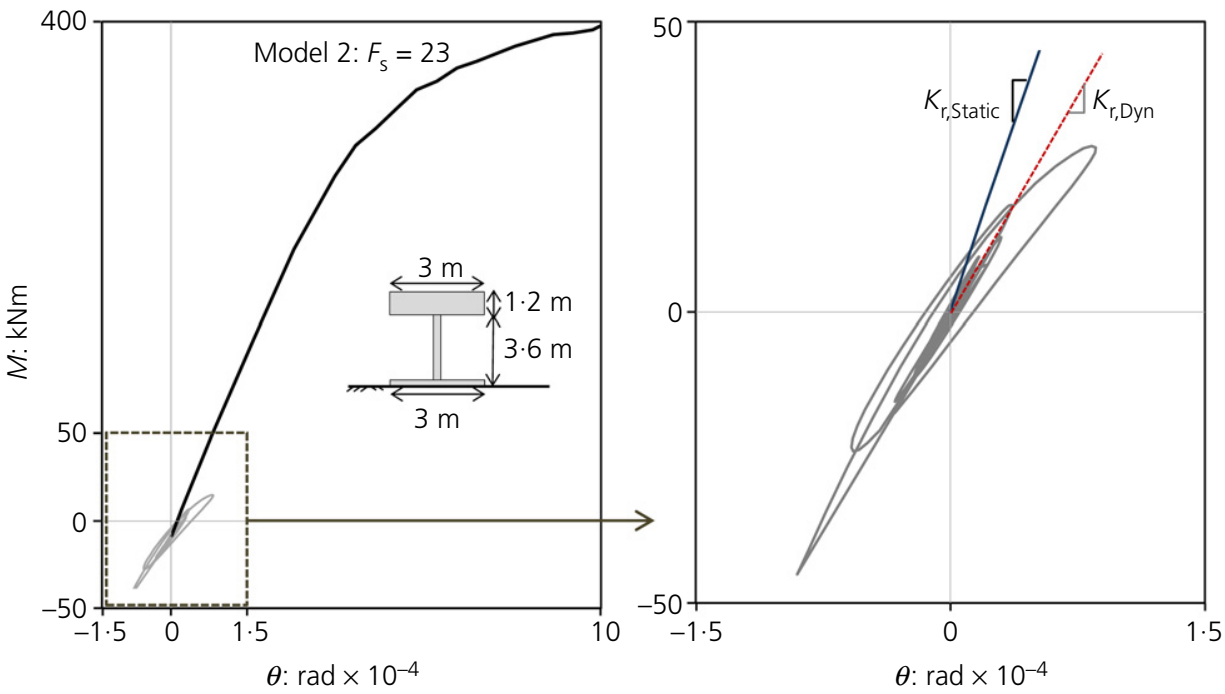

(b)

Figure 20. Comparison of measured dynamic to static small-strain stiffness for: (a) model 3: $F_{\mathrm{s}}=15$; and (b) model 2: $F_{\mathrm{s}}=23$

Table 7. Ratio between the experimentally derived static and dynamic stiffness's. Comparison is provided with the factor (1-0.2a $)$ of Equation 21

\begin{tabular}{|c|c|c|c|c|c|}
\hline $\begin{array}{l}\text { Model } \\
\text { ID }\end{array}$ & $\begin{array}{c}K_{\mathrm{r}, \text { Static }} \text { tests: } \\
\text { MNm }\end{array}$ & $\begin{array}{l}K_{\text {r,Dyn }} \text { tests: } \\
\text { MNm }\end{array}$ & $\begin{array}{l}K_{r, \text { Dyn }} / K_{r, \text { Static }} \text { Tests: } \\
\text { dimensionless }\end{array}$ & $\begin{array}{c}\left(1-0.2 a_{0}\right) \text { Equation 21: } \\
\text { dimensionless }\end{array}$ & $\begin{array}{c}\text { Difference ratio tests against } \\
\text { Equation } 21: \%\end{array}$ \\
\hline 1 & 406 & 389 & 0.96 & 0.95 & $1 \cdot 15$ \\
\hline 2 & 864 & 775 & 0.89 & 0.90 & 0.82 \\
\hline 3 & 2260 & 2131 & 0.94 & 0.95 & $1 \cdot 11$ \\
\hline 4 & 4792 & 4340 & 0.90 & 0.92 & 1.23 \\
\hline 5 & 373 & 366 & 0.98 & 0.93 & 1.05 \\
\hline 6 & 840 & 748 & 0.89 & 0.87 & 1.02 \\
\hline 7 & 2076 & 1947 & 0.94 & 0.96 & 0.98 \\
\hline 8 & 4391 & 3921 & 0.89 & 0.89 & 0 \\
\hline
\end{tabular}


International Journal of Physical Modelling in Geotechnics Volume 18 Issue 6
Static and dynamic rocking stiffness

of shallow footings on sand:

centrifuge modelling

Taeseri, Laue, Martakis, Chatzi and

Anastasopoulos

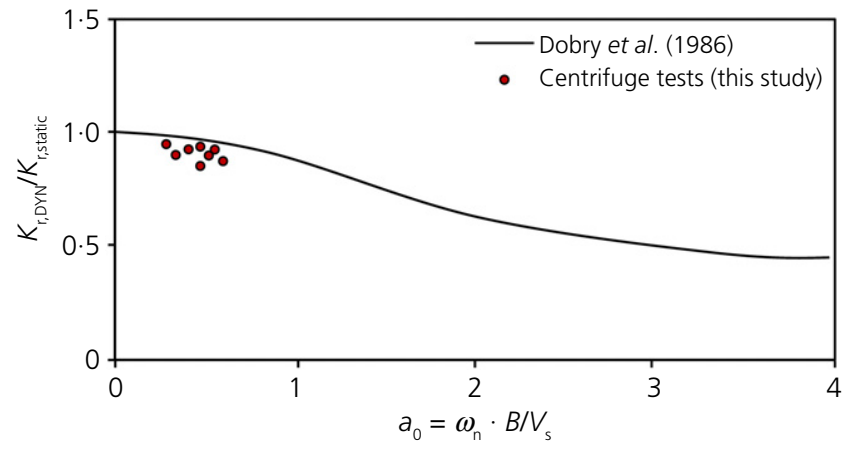

Figure 21. Ratio of dynamic-to-static rocking stiffness with respect to dimensionless frequency $a_{0}$ and comparison with the analytical solution of Dobry and Gazetas (1986)

measure the dynamic rocking stiffnesses. The adopted tubeactuator was also used to apply the SASW technique in-flight. In this case, the spherical projectiles were aimed at a target plate resting on the model surface. Therefore, the developed actuator can be seen to be versatile, offering various testing possibilities.

The centrifuge model tests were shown to fully confirm the formulas proposed by Dobry and Gazetas (1986) and Gazetas (1991a, 1991b). To the best of the authors' knowledge, the latter had only been verified against $1 \boldsymbol{g}$ experiments (Erden, 1974; Gazetas and Stokoe, 1991), in which the measured damping in swaying-rocking was found to be only half of the theoretical. While this was mainly attributed to boundary conditions, the inherent inability of $1 \boldsymbol{g}$ physical modelling to realistically reproduce soil confining pressures could have been an additional factor. Therefore, the centrifuge model tests presented herein, can be seen to offer a resolution of this issue. The good agreement with the analytical solutions serves as a confirmation of the validity of the experimental procedure. This is of particular importance, as the latter is employed (in further publications) to experimentally measure stiffnesses and moment capacities of a variety of embedded foundations on level and inclined ground, for which analytical solutions hardly exist.

\section{Acknowledgements}

The authors thank Professor S. M. Springman for her kind support and valuable suggestions for the experiments conducted. Professor A. Elgamal for his kind invitation and support with Professor J. McCartney in conducting the centrifuge experiments at UCSD. The authors also acknowledge the valuable support of the master students (S. Britschgi, C. Buss, L. Lampach, M. Lee, R. Sidler, D. T. Tran, R. Wiederkehr) and technicians (E. Bleiker, M. Iten, C. Latham) involved in this research study.

\section{REFERENCES}

Anastasopoulos I and Kontoroupi Th (2014) SDOF system rocking on inelastic soil: development of simplified nonlinear analysis method. Soil Dynamics and Earthquake Engineering 56: 28-43, https://doi.org/10.1016/j.soildyn.2013.10.001.

Anastasopoulos I, Gazetas G, Loli M, Apostolou M and Gerolymos N (2010) Soil failure can be used for seismic protection of structures. Bulletin of Earthquake Engineering 8(2): 309-326.

Anastasopoulos I, Kourkoulis R, Gelagoti F and Papadopoulos E (2012) Rocking response of SDOF systems on shallow improved sand: an experimental study. Soil Dynamics and Earthquake Engineering 40: 15-33, https://doi.org/10.1016/j.soildyn.2012.04.006.

Antonellis G, Gavras AG, Panagiotou M et al. (2015) Shake table test of large-scale bridge columns supported on rocking shallow foundations. Journal of Geotechnical and Geoenvironmental Engineering, ASCE 141(5): 04015009.

Arnold A (2011) Tragverhalten von nicht starren Flachfundationen unter Berücksichtigung der lokalen Steifigkeitsverhältnisse (No. 19516). vdf Hochschulverlag AG, Zurich, Switzerland (in German).

Buchheister JA (2012) Verflüssigungspotenzial von reinem und siltigem Sand unter multiaxialer Belastung (No. 18312). vdf Hochschulverlag AG, Zurich, Switzerland (in German).

Buss C and Lampach L (2015) Identification of Dynamic Soil-Structure Interaction Effects on a SDOF System. Master project, ETH Zürich, Zurich, Switzerland.

Cheney JA, Brown RK, Dhat NR and Hor OYZ (1990) Modeling free-field conditions in centrifuge models. Journal of Geotechnical Engineering, ASCE 116(9): 1347-1367.

Chikatamarla R, Laue J and Springman SM (2006) Centrifuge scaling laws for guided free fall events including rockfalls. International Journal of Physical Modelling in Geotechnics 6(2): 15-26, http://dx.doi.org/10.1680/ijpmg.2006.060202.

Ciampoli M and Pinto PE (1995) Effects of soil-structure interaction on inelastic seismic response of bridge piers. Journal of Structural Engineering 121(5): 806-814.

Deng $L$ and Kutter BL (2012) Characterization of rocking shallow foundations using centrifuge model tests. Earthquake Engineering \& Structural Dynamics 41(5): 1043-1060.

Dobry R and Gazetas G (1986) Dynamic response of arbitrarily shaped foundations. Journal of Geotechnical Engineering 112(2): 109-135.

Erden SM (1974) Influence of Shape and Embedment on Dynamic Foundation Response. Doctoral dissertation, University of Massachusetts, Amherst, MA, USA.

Gajan S and Kutter BL (2008) Capacity, settlement, and energy dissipation of shallow footings subjected to rocking. Journal of Geotechical and Geoenvironmental Engineering, ASCE 134(8): 1129-1141.

Gajan S, Kutter BL, Phalen JD, Hutchinson TC and Martin GR (2005) Centrifuge modeling of load-deformation behavior of rocking shallow foundations. Soil Dynamics and Earthquake Engineering 25(7): 773-783.

Garnier J, Gaudin C, Springman SM et al. (2007) Catalogue of scaling laws and similitude questions in geotechnical centrifuge modelling. International Journal of Physical Modelling in Geotechnics 7(3): 1, http://dx.doi.org/10.1680/ijpmg.2007.070301.

Gazetas G (1991a) Formulas and charts for impedances of surface and embedded foundations. Journal of Geotechnical Engineering, ASCE 117(9): 1363-1381.

Gazetas G (1991b) Foundation vibrations. In Foundation Engineering Handbook. Springer, Boston, MA, USA, pp. 553-593.

Gazetas G and Stokoe KH (1991) Free vibration of embedded foundations: theory versus experiment. Journal of Geotechnical Engineering, ASCE 117(9): 1382-1401. 
International Journal of Physical Modelling in Geotechnics Volume 18 Issue 6
Static and dynamic rocking stiffness

of shallow footings on sand:

centrifuge modelling

Taeseri, Laue, Martakis, Chatzi and

Anastasopoulos
Gazetas G, Apostolou M and Anastasopoulos I (2003) Seismic uplifting of foundations on soft soil, with examples from Adapazari (Izmit 1999, Earthquake). In BGA International Conference on Foundations: Innovations, Observations, Design and Practice (Newson TA (ed.)). ICE Publishing, London, UK, vol. 25, pp. 37-50.

Gazetas G, Anastasopoulos I, Gerolymos N, Mylonakis G and Syngros C (2006) The collapse of the Hanshin expressway (Fukae) Bridge, Kobe 1995: soil-foundation-structure interaction, reconstruction, seismic isolation. Entwicklungen in der Bodenmechanik, Bodendynamik und Geotechnik (Rackwitz F (ed.)). Springer, Berlin, Heidelberg, Germany, pp. 93-120.

Gazetas G, Anastasopoulos I, Adamidis O and Kontoroupi T (2013) Nonlinear rocking stiffness of foundations. Soil Dynamics and Earthquake Engineering 47: 83-91, https://doi.org/10.1016/ j.soildyn.2012.12.011.

Holzer TL and Youd TL (2007) Liquefaction, ground oscillation, and soil deformation at the Wildlife Array, California. Bulletin of the Seismological Society of America 97(3): 961-976.

Ishibashi I and Zhang X (1993) Unified dynamic shear moduli and damping ratios of sand and clay. Soils and Foundations 33(1): 182-191.

Kapogianni E, Sakellariou M and Laue J (2016) Experimental investigation of reinforced soil slopes in a geotechnical centrifuge, with the use of optical fibre sensors. Geotechnical and Geological Engineering 35(2): 585-605.

Kausel E (2010) Early history of soil-structure interaction. Soil Dynamics and Earthquake Engineering 30(9): 822-832.

Koga Y and Matsuo O (1990) Shaking table tests of embankments resting on liquefiable sandy ground. Soils and Foundations 30(4): $162-174$.

Kokkali P, Anastasopoulos I, Abdoun T and Gazetas G (2014) Static and cyclic rocking on sand: centrifuge versus reduced scale $1 \mathrm{~g}$ experiments. Geotechnique 64(11): 865-880, http://dx.doi.org/ 10.1680/geot.14.P.064

Kramer SL (1996) Geotechnical Earthquake Engineering. Pearson Education, Upper Saddle River, NJ, USA.

Laue J, Nater P, Springman SM and Grämiger E (2002) Preparation of soil samples in drum centrifuges. In Proceedings of the International Conference of Physical Modelling in Geotechnical Engineering. IOS Press, Amsterdam, the Netherlands, pp. 143-148.

Laue J, Springman SM, Gautray J et al. (2015) 15 years of experience using a physical model exercise in a masters' course. In Proceedings of the 8th International Conference on Physical Modelling in Geotechnics 2014 (ICPMG 2014), Perth, Australia (Gaudin C and White D (eds)). Centre for Offshore Foundation Systems, The University of Western Australia, Perth, Australia, vol. 1, pp. 445-450.

Lo Presti D, Pedroni S and Crippa V (1992) Maximum dry density of cohesionless soils by pluviation and by ASTM D 4253-83: a comparative study. Geotechnical Testing Journal 15(2): 180-189.

Lou M, Wang H, Chen X and Zhai Y (2011) Structure-soil-structure interaction: literature review. Soil Dynamics and Earthquake Engineering 31(12): 1724-1731.

Luco JE and Contesse L (1973) Dynamic structure-soil-structure interaction. Bulletin of the Seismological Society of America 63(4): 1289-1303.

Luong MP (1994) Efficiency of a stress-wave mitigation barrier. In Proceedings of the International Conference on Centrifuge Modelling (Centrifuge 94). Balkema, Singapore, pp. 283-288.

Martakis P (2016) A Centrifuge - Experimental Study in the Soil and Structure Interaction Effect on a SDOF System. Master thesis, Eidgenössische Technische Hochschule ETH Zürich, Zurich, Switzerland.
Martakis P, Taeseri D, Chatzi E and Laue JA (2016) Centrifuge-based experimental and analytical study of the soil and structure interaction effect. 11th HSTAM International Congress on Mechanics, Athens, Greece. Hellenic Society of Theoretical and Applied Mechanics, Athens, Greece, pp. 58-63.

Mergos PE and Kawashima K (2005) Rocking isolation of a typical bridge pier on spread foundation. Journal of Earthquake Engineering 9(2): 395-414.

Micro-Epsilon (1997) Betriebsanleitung optoNCDT 1400 - Intelligente Laseroptische Wegmessung. Micro-Epsilon, Ortenburg, Deutschland (in German).

Morales WF (2015) River Dyke Failure Modeling Under Transient Water Conditions, vol. 247. vdf Hochschulverlag AG, Zurich, Switzerland.

Murillo CA, Thorel L and Caicedo B (2009) Spectral analysis of surface waves method to assess shear wave velocity within centrifuge models. Journal of Applied Geophysics 68(2): 135-145.

Mylonakis G and Gazetas G (2000) Seismic soil-structure interaction: beneficial or detrimental? Journal of Earthquake Engineering 4(3): 277-301.

Nater P (2002) Construction of models in the ETH Zurich drum centrifuge. In Constitutive and Centrifuge Modelling: Two Extremes (Springman SM (ed.)). Balkema, Rotterdam, the Netherlands, pp. 155-161.

Nater P (2007) Belastungs-und Verformungsverhalten von geschichteten Bodensystemen unter starren Kreisfundationen (No. 16319). vdf Hochschulverlag AG, Zurich, Switzerland (in German).

Nazarian S, Stokoe II, Kenneth H and Hudson WR (1983) Use of Spectral Analysis of Surface Waves Method for Determination of Moduli and Thicknesses of Pavement Systems. Transportation Research Board, Austin, TX, USA (No. 930).

NEHRP (National Earthquake Hazards Reduction Program) (1997) Recommended Provisions for Seismic Regulations for New Buildings and Other Structures, Parts 1 and 2. Building Seismic Safety Council, Washington, DC, USA.

Paolucci R, Shirato M and Yilmaz MT (2007) Seismic behavior of shallow foundations: shaking table experiments vs numerical modeling. Earthquake Engineering and Structural Dynamics 37(4): 577-595.

Pecker A (2003) Aseismic foundation design process, lessons learned from two major projects: the Vasco de Gama and the Rion Antirion bridges. In ACI International Conference on Seismic Bridge Design and Retrofit. University of California at San Diego, La Jolla, CA, USA.

Pecker A and Chatzigogos CT (2010) Nonlinear soil structure interaction: impact on the seismic response of structures. In Earthquake Engineering in Europe (Garevski M and Ansal A (eds)). Springer, Dordrecht, the Netherlands, pp. 79-103.

Schofield AN (1980) Cambridge geotechnical centrifuge operations. Géotechnique 30(3): 227-268, http://dx.doi.org/10.1680/geot.1980. 30.3.227.

Seed HB, Wong RT, Idriss IM and Tokimatsu K (1986) Moduli and damping factors for dynamic analyses of cohesionless soils. Journal of Geotechnical Engineering 112(11): 1016-1032.

Selesnick IW and Burrus CS (1998) Generalized digital Butterworth filter design. IEEE Transactions on Signal Processing 46(6): 1688-1694.

Sieffert J and Cevaer F (1995) Handbook of Impedance Functions. Editions Ouest-France, Nantes, France, French edn.

Siemer T (1996) Zentrifugenmodellversuche zur dynamischen Wechselwirkung zwischen Bauwerk und Baugrund infolge stoßartiger Belastung. Inst. für Grundbau, Bochum, Germany (in German). 
International Journal of Physical Modelling in Geotechnics Volume 18 Issue 6
Static and dynamic rocking stiffness

of shallow footings on sand:

centrifuge modelling

Taeseri, Laue, Martakis, Chatzi and

Anastasopoulos
Siemer TH and Jessberger HL (1994) Wave propagation and active vibration control in sand. In Proceedings of the International Conference on Centrifuge Modeling-Centrifuge (Leung CF, Lee FH and Tan TS (eds)). Balkema, Singapore, vol. 94, pp. 307-312.

Springman SM, Laue J, Boyle R, White J and Zweidler A (2001) The ETH Zurich geotechnical drum centrifuge. International Journal of Physical Modelling in Geotechnics 1(1): 59-70, http://dx.doi.org/ 10.1680/ijpmg.2001.010107.

Stokoe KH, Wright SG, Bay JA and Roesset JM (1994) Characterization of geotechnical sites by SASW method. In Geophysical

Characterization of Sites (Woods RD (ed.)). Balkema, Rotterdam, the Netherlands, pp. 15-25.

Terzaghi K, Peck RB and Mesri G (1996) Soil Mechanics in Engineering Practice. John Wiley \& Sons, New York, NY, USA.
Testa A, Gallo D and Langella R (2004) On the processing of harmonics and interharmonics: using Hanning window in standard framework. IEEE Transactions on Power Delivery 19(1): 28-34.

Yang J, Li JB and Lin G (2006) A simple approach to integration of acceleration data for dynamic soil-structure interaction analysis. Soil Dynamics and Earthquake Engineering 26(8): 725-734.

Zeghal M and Elgamal AW (1994) Analysis of site liquefaction using earthquake records. Journal of Geotechnical Engineering 120(6): 996-1017.

Zeghal M, Elgamal AW and Parra E (1996) Analyses of site liquefaction using downhole array seismic records. In Proceedings of the 11th World Conference on Earthquake Engineering. Pergamon, Oxford, UK, vol. 371, pp. 23-28.

\section{How can you contribute?}

To discuss this paper, please email up to 500 words to the editor at journals@ice.org.uk. Your contribution will be forwarded to the author(s) for a reply and, if considered appropriate by the editorial board, it will be published as discussion in a future issue of the journal.

International Journal of Physical Modelling in Geotechnics relies entirely on contributions from the civil engineering profession (and allied disciplines). Information about how to submit your paper online is available at www. icevirtuallibrary.com/page/authors, where you will also find detailed author guidelines. 